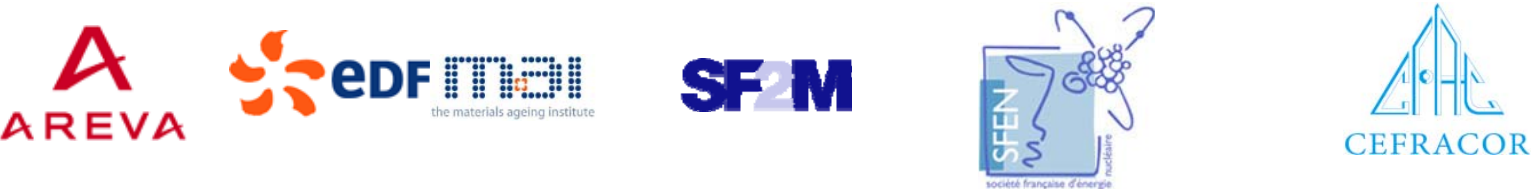

\section{MIN口S}

Centre of Excellence for Nuclear Materials

\section{Workshop}

Materials Innovation for Nuclear Optimized Systems
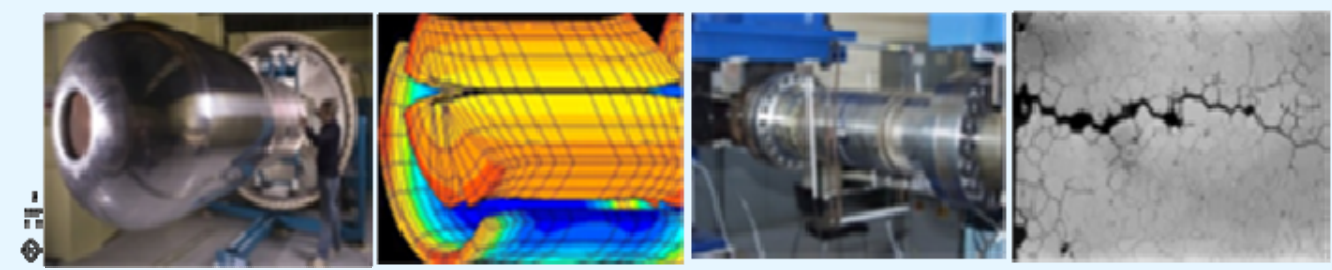

December 5-7, 2012, CEA - INSTN Saclay, France

\section{William J. WEBER}

University of Tennessee (USA)

Irradiation Effects in Materials for Nuclear Applications

Workshop organized by:

Christophe GALLÉ, CEA/MINOS, Saclay - christophe.galle@cea.fr Constantin MEIS, CEA/INSTN, Saclay - constantin.meis@cea.fr 


\title{
Irradiation Effects in Materials for Nuclear Applications
}

\author{
William J. WEBER ${ }^{1}$ \\ ${ }^{1}$ Department of Materials Science \& Engineering, University of Tennessee (Knoxville, TN, USA)
}

There has been a resurgence of international interest in nuclear energy as a clean energy source, and the continued success of existing nuclear reactors, the promise of advanced reactor designs, and the acceptance of used nuclear fuel disposition options are dependent on the performance of materials in extreme nuclear environments. The effects of irradiation on materials properties and performance are critical to safe and reliable reactor operations, efficient use of uranium resources, reduced production of nuclear waste, and acceptable used nuclear fuel disposition [1]. This lecture will provide an introduction to irradiation effects in materials for nuclear applications. The fundamental irradiation damage mechanisms will be described, and the effects of different irradiation environments for nuclear fuels (nuclear fission damage), structural components (neutron damage), and used nuclear fuel and nuclear waste forms (alpha decay damage) will be discussed.

Irradiation damage in materials for nuclear applications primarily results from the production of energetic particles in fission, nuclear reaction and radioactive decay events. The interaction of these energetic particles (fission products, fast neutrons, protons, alphas, and recoil nuclei) with materials results in the production of atomic-scale defects from ballistic collisions and introduction of new chemical elements. In the case of high-energy fission products, the intense ionization along the fission product path can also introduce defects or damage [2]. These irradiation damage processes control the long-term evolution of the materials response to the production and diffusion of defects, fission products and nuclear reaction products. With the exception of fast neutrons, the energetic particles produced in nuclear environments are charged ions that can be also be produced using ion accelerator facilities, such as the JANNuS facility in France [3] or facilities in the USA [4, 5]. Even in the case of a fast neutron, 50 to $100 \mathrm{keV}$ of kinetic energy is transferred on average to a primary knock-on atom (PKA) [6], which is essentially an energetic ion that produces a cascade of displaced atoms through screened-Coulomb collisions, as illustrated in Fig. 1 for silicon carbide [7].

Ion-beam irradiation techniques can be effective in simulating neutron irradiation effects $[6,8]$, fission damage [9] and alpha-decay damage [10] on short laboratory time scales over a large range of experimental conditions in order to develop more detailed scientific understanding and predictive models of the complex evolution microstructure and phase changes under irradiation. The unique effects of ion irradiation and the use of ions to study fast neutron irradiation effects is a critical topic, since development and qualification of new structural materials requires neutron doses that are too high to be obtained in existing nuclear test reactors or spallation neutron sources.

The advantages and disadvantages of using ions to simulate nuclear radiation environments will be reviewed, with specific examples provided. The integration of computer simulations into these irradiation studies have advanced the interpretation of experimental results

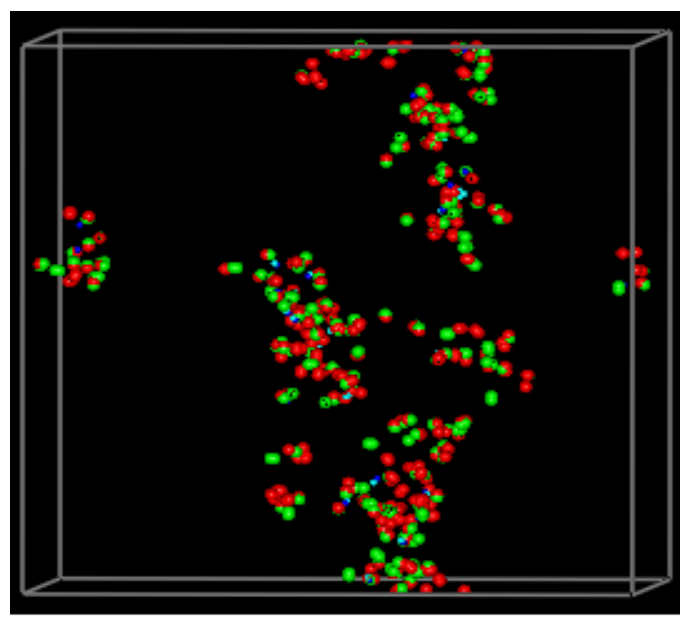

Fig. 1: Defects created by a $50 \mathrm{keV} \mathrm{Si}$ PKA cascade in silicon carbide (only defects are shown) [7]. 
$[2,7]$ and provided a more comprehensive atomic-level understanding and predictive models of irradiation damage processes.

\section{References}

[1] Y. Guerin, G. S. Was, S. J. Zinkle, Materials Challenges for Advanced Nuclear Energy Systems. MRS Bulletin 34 [1] : 10-14 (2009).

[2]R. Devanathan, W. J. Weber, Simulation of collision cascades and thermal spikes in ceramic. Nucl. Instrum. and Methods Phys. Res. B 268 : 2857-2862 (2010).

[3] Y. Serruys, M.-O. Ruault, P. Trocellier, S. Henry, O. Kaitasov, Ph. Trouslard, Multiple ion beam irradiation and implantation: JANNUS project. Nucl. Instrum. and Methods Phys. Res. B 240 : 124-127 (2005).

[4] I. O. Usov, D. J. Devlin, J. Won, A. Kossoy, J. A. Valdez, Y. Q. Wang, K. E. Sickafus, Medium energy ion irradiation capability for studies of radiation damage effects over a wide temperature range. Nucl. Instrum. and Methods Phys. Res. B 269 : 2734-2739 (2011).

[5] S. Thevuthasan, C. H. F. Peden, M. H. Engelhard, D. R. Baer, G. S. Herman, W. Jiang, Y. Liang, W. J. Weber, The Ion Beam Materials Analysis Laboratory at the Environmental Molecular Sciences Laboratory. Nucl. Instrum. and Methods in Phys. Res. A 420 [1-2]: 81-89 (1999).

[6] G. S. Was, Fundamentals of Radiation Materials Science (Springer, Heidelberg, 2007).

[7] F. Gao, W. J. Weber, Atomic-level study of ion-induced nanoscale disordered domains in silicon carbide. Applied Physics Letters 82 [6] : 913-915 (2003).

[8] T. R. Allen, J. Gan, J. I. Cole, M. K. Miller, J. T. Busby, S. Shutthanandan, S. Thevuthasan, Radiation response of a 9 chromium oxide dispersion strengthen steel to heavy ion irradiation. $\mathrm{J}$. Nuclear Materials $375: 26-37$ (2008).

[9] W. Li, M. Lang, A. J. W. Gleadow, M. V. Zdorovets, R. C. Ewing, Thermal annealing of unetched fission tracks in apatite. Earth and Planetary Science Letters 321-322 : 121-127 (2012).

[10] S. Moll, G. Sattonnay, L. Thomé, J. Jagielski, C. Decorse, P. Simon, I. Monnet, W. J. Weber, Irradiation damage in $\mathrm{Gd}_{2} \mathrm{Ti}_{2} \mathrm{O}_{7}$ single crystals: Ballistic versus ionization processes, Physical Review B 84 [6]: 064115 (2011). 


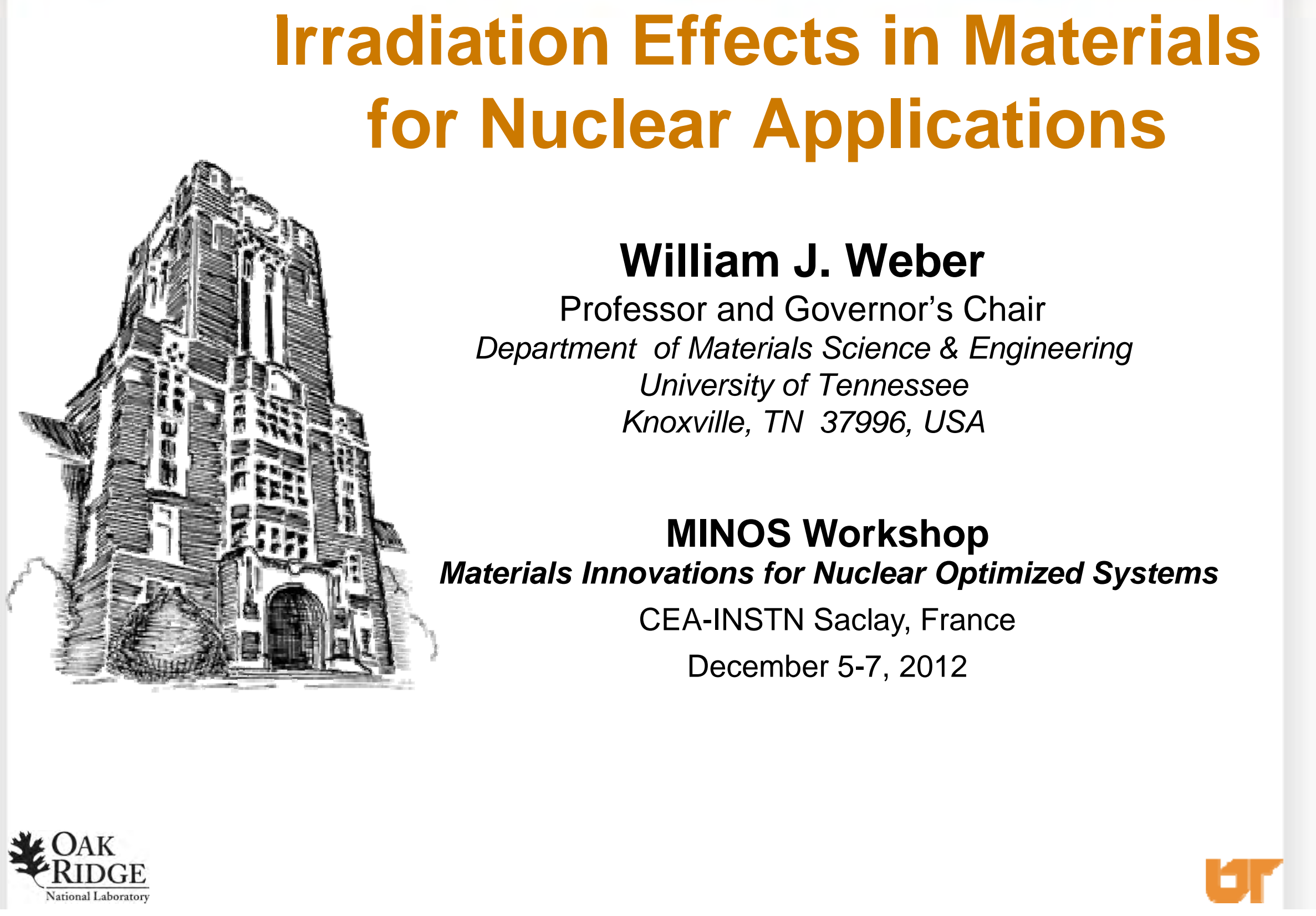




\section{Nuclear Radiation Environments of Interest}

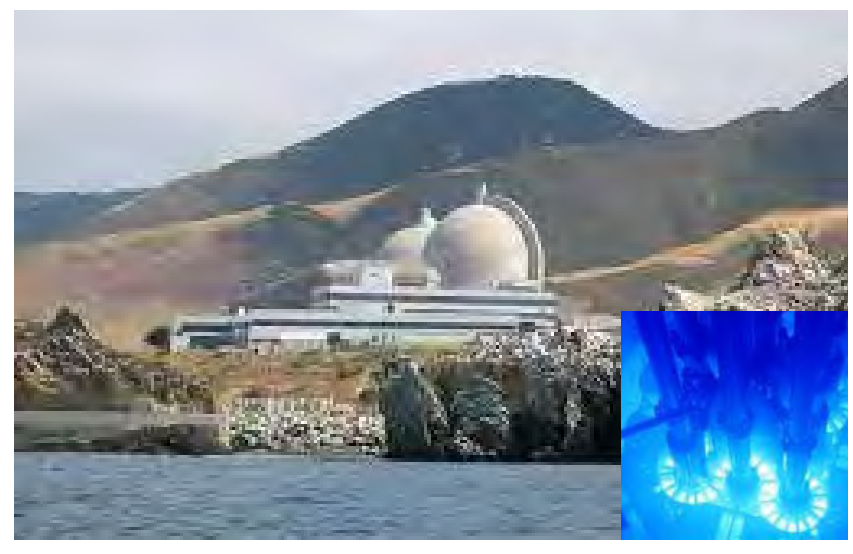

Nuclear (Fission) Power

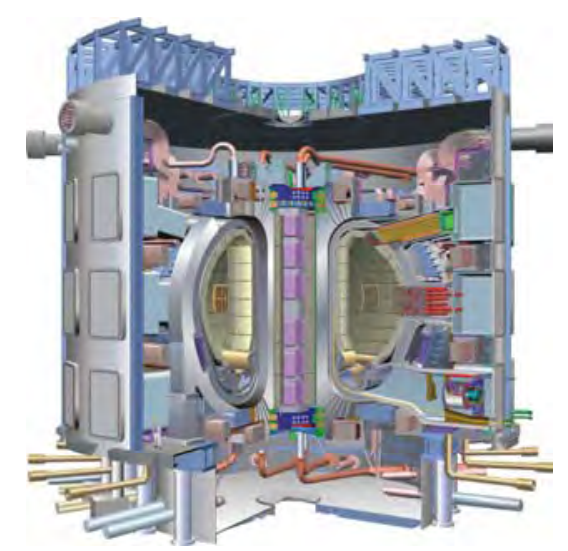

Fusion Reactor

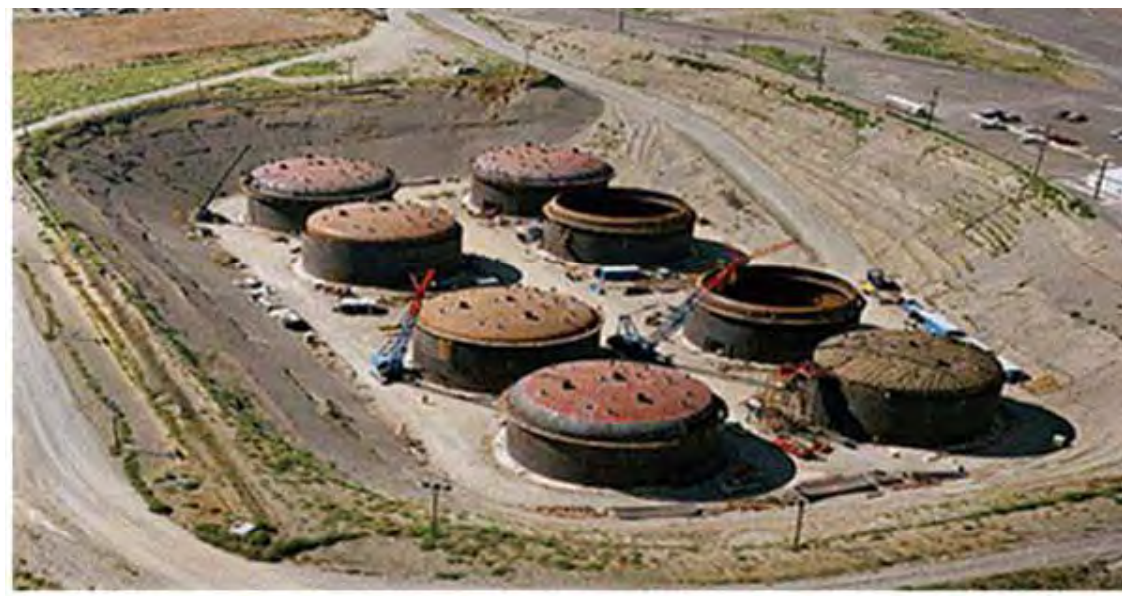

Nuclear Waste 


\section{Radiation Damage in Nuclear Materials}

$>$ Fundamental Radiation Damage Processes

$>$ Nuclear Fuel (in reactor)

- Fission Damage

- Accumulation of Fission \& Transmutation Products

$>$ Structural Components

- Fast Neutron Damage

- Helium \& Hydrogen Production

- Other Transmutation Products

$>$ Nuclear Waste Forms and Used Nuclear Fuel

- Fission Damage (negligible)

- Beta Decay Damage (important in short-term $-<600$ years)

- Alpha Decay Damage (important over long-term - million years)

$>$ Use of Ion Beams to Study Radiation Damage Processes 


\section{Defect Production from Ballistic Processes}

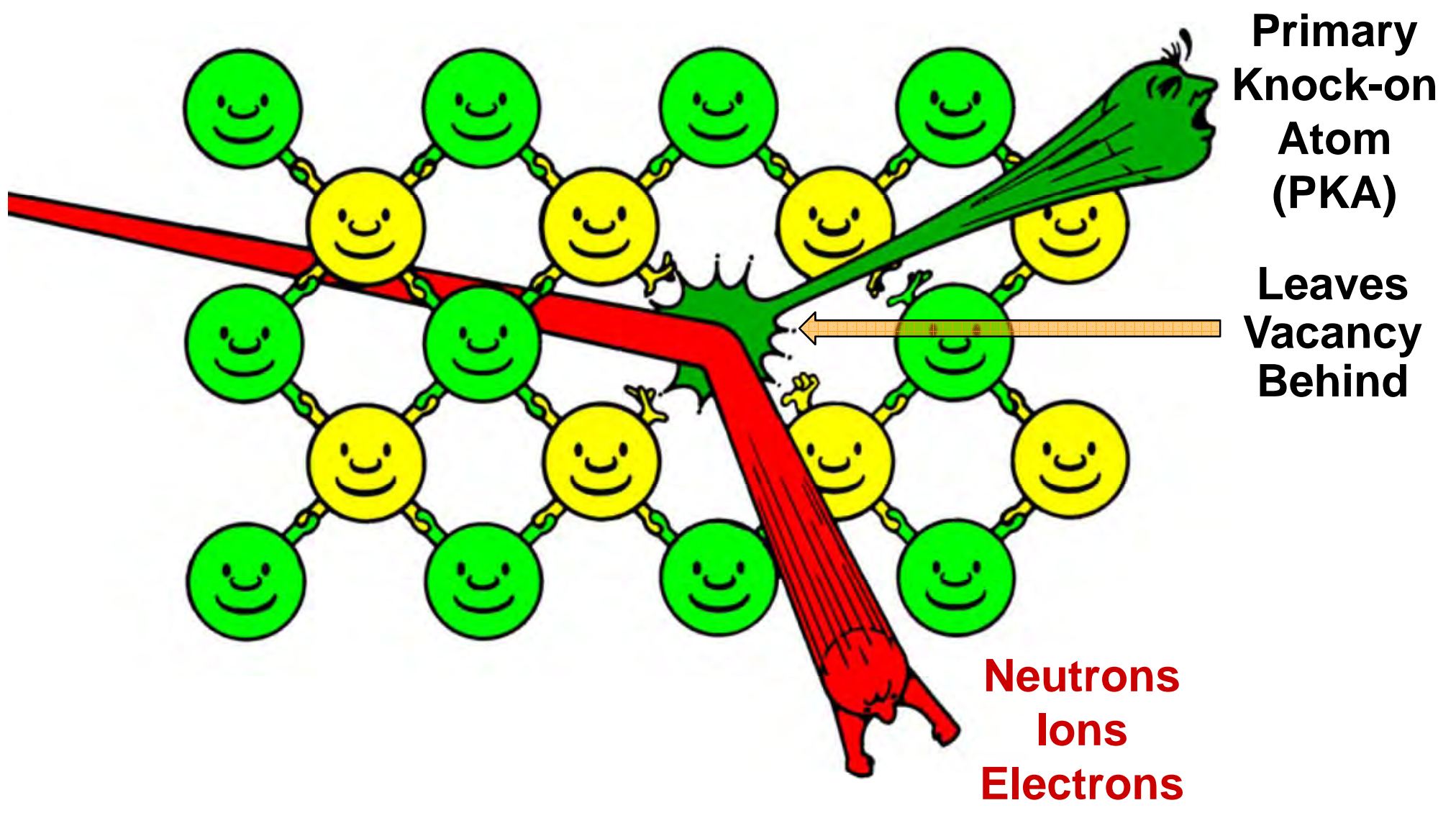

$>$ Energetic neutrons, ions and electrons displace atoms

$>$ Energetic Primary Knock-on Atoms (PKAs) create a cascade of ballistic collisions between atoms 


\section{Radiation Damage in Nuclear Materials Primarily Caused by Energetic lons created by Fission, Fast Neutron Collisions, or Radioactive Decay}

Using Ion Beams to Study Irradiation Effects in Nuclear Materials has become a Widely-Practiced Approach (particularly with lack of fast neutron test facilities)

$>$ Important for separate effects studies

$>$ Use for development \& validation of predictive models

$>$ Offers wider range \& more control of irradiation conditions 


\section{Some Experimental Research Facilities}
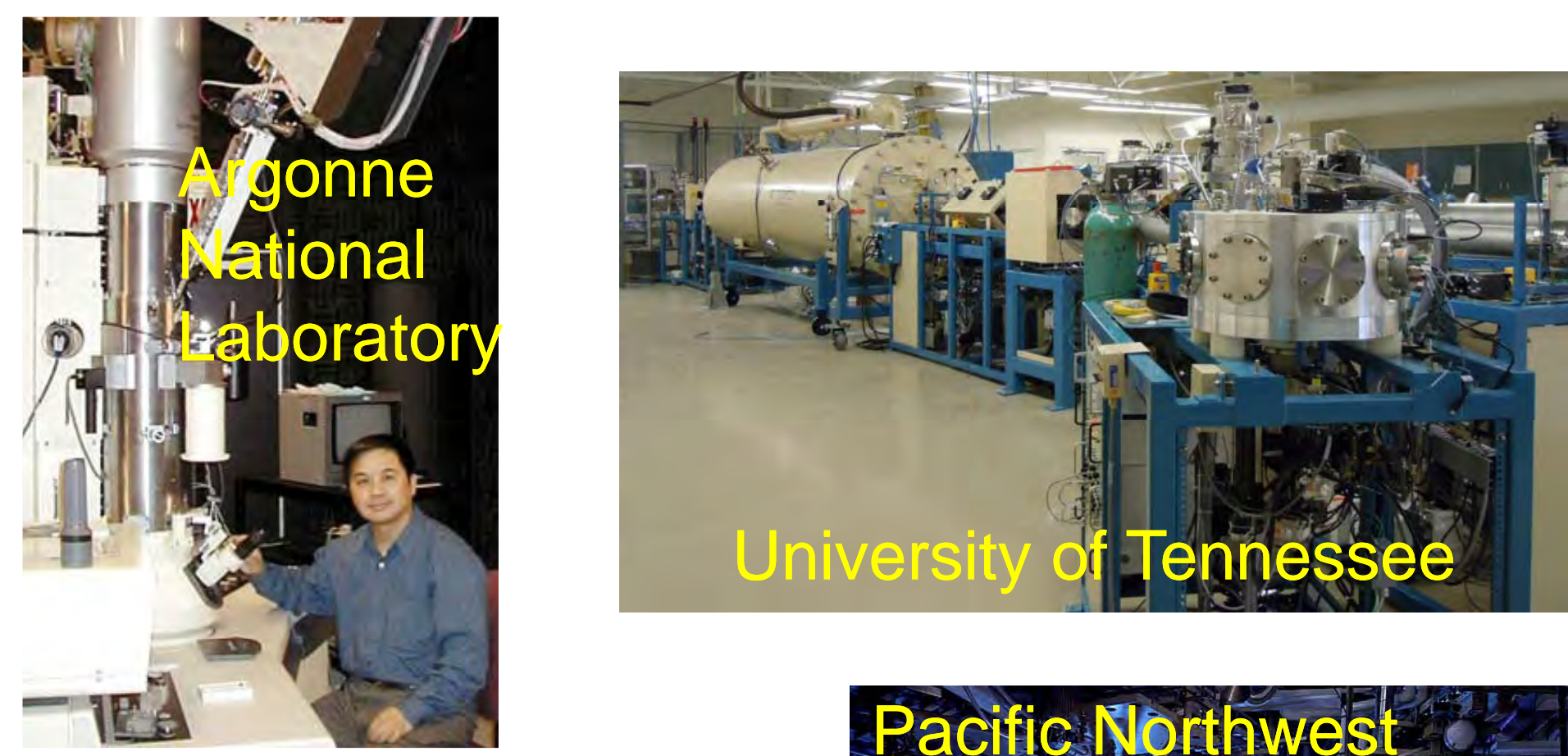

University of Tennessee
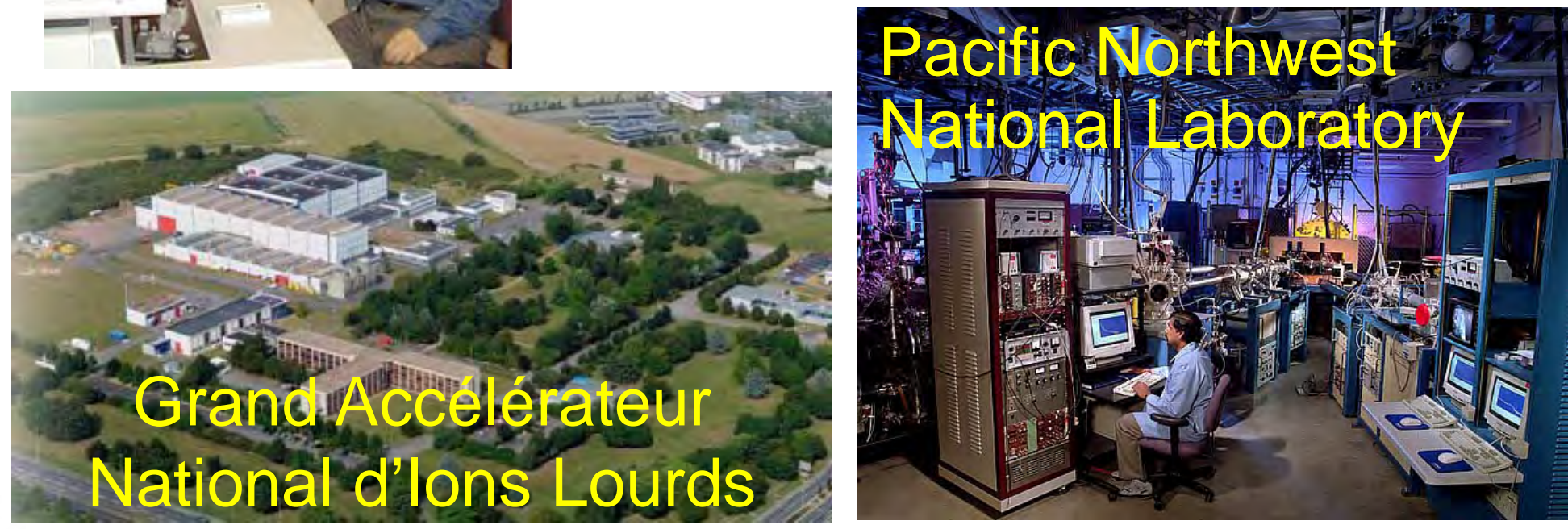


\section{Fission Damage}




\section{Nuclear Fission}

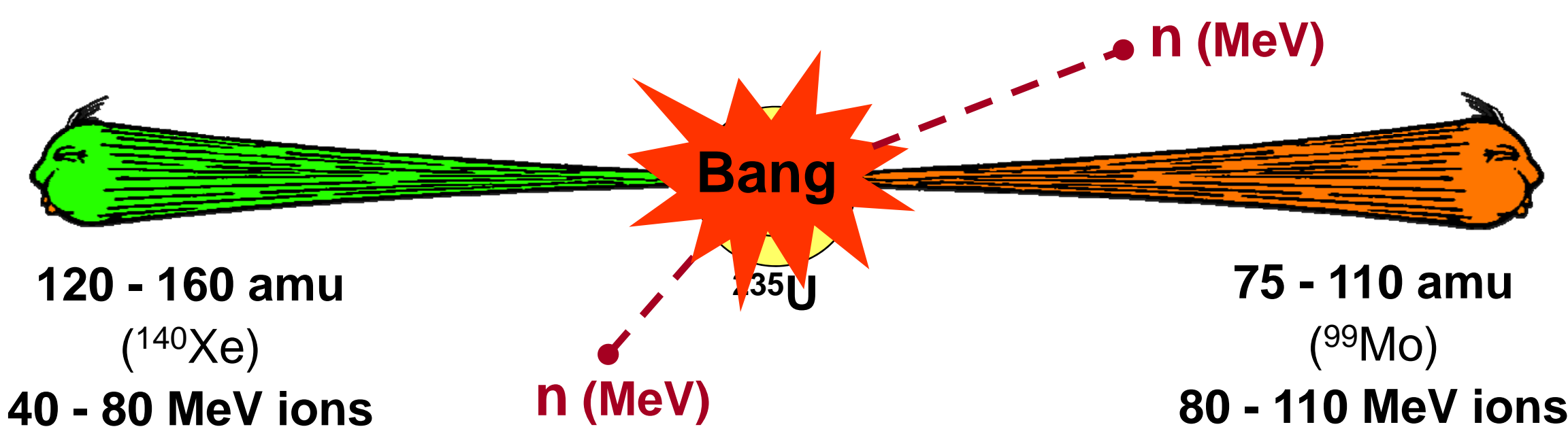

$>$ Fission products (high-energy ions) lose energy creating linear tracks of defects or structural changes in materials

$>$ Ballistic collision cascade near end of range

$>$ Fission tracks: nano radii ( $\sim 5 \mathrm{~nm})$ and macro lengths ( $\sim 10$ microns)

$>$ Accumulation of fission products \& gases affects microstructure

$>$ In $\sim 0.2$ to $0.4 \%$ of fission events, helium is produced (ternary fission) 


\section{Fission Product Energy Loss}

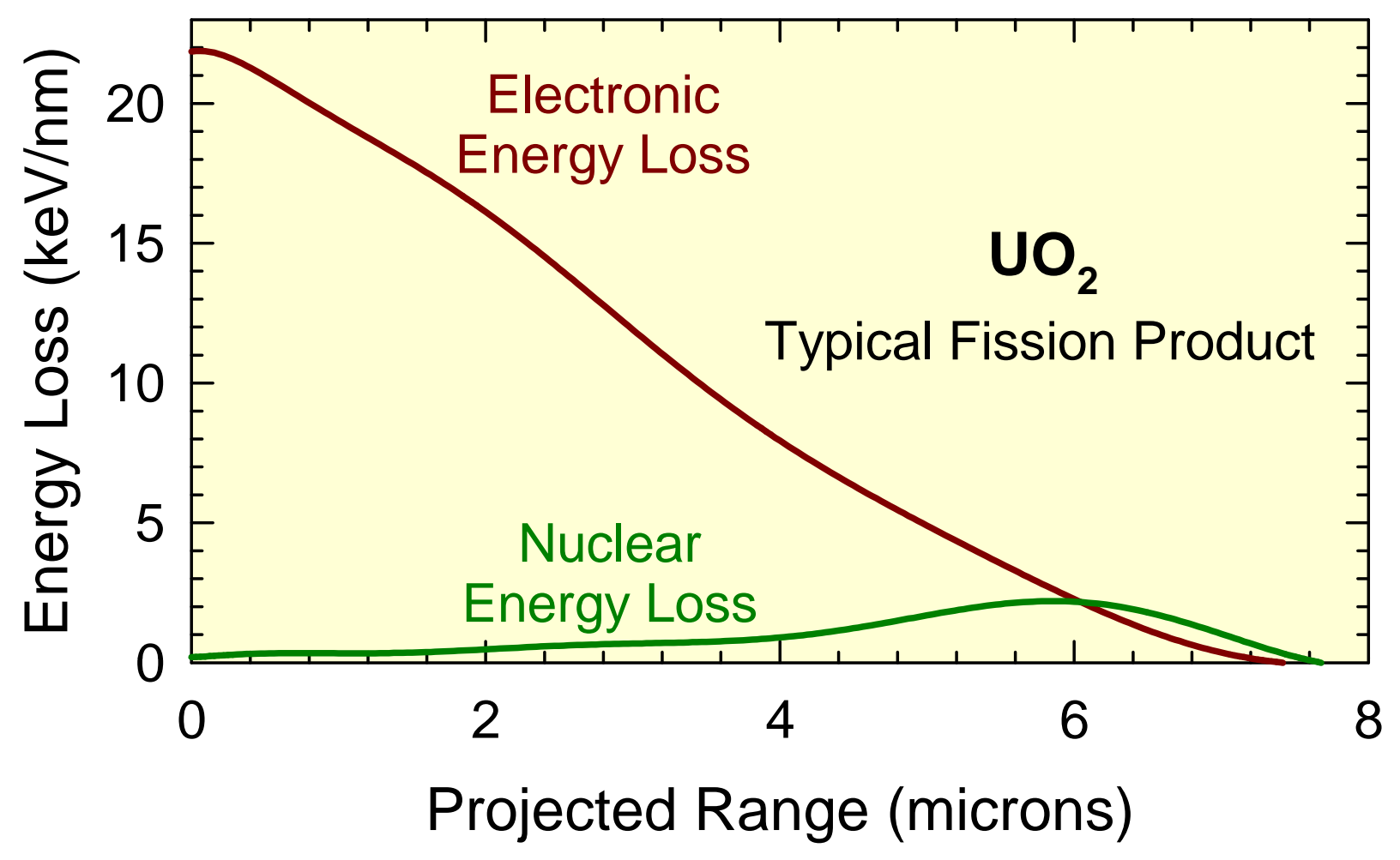

Electronic Energy Loss: $\quad$ 1) 20,000 defects along fission track (MD Simulations)

2) Dislocation loops along fission track

Nuclear Energy Loss: $\quad$ 1) $\sim 65,000$ displaced atoms in fission product cascade

2) Defect clusters in cascade 


\section{Radiation Damage in Nuclear Fuel}

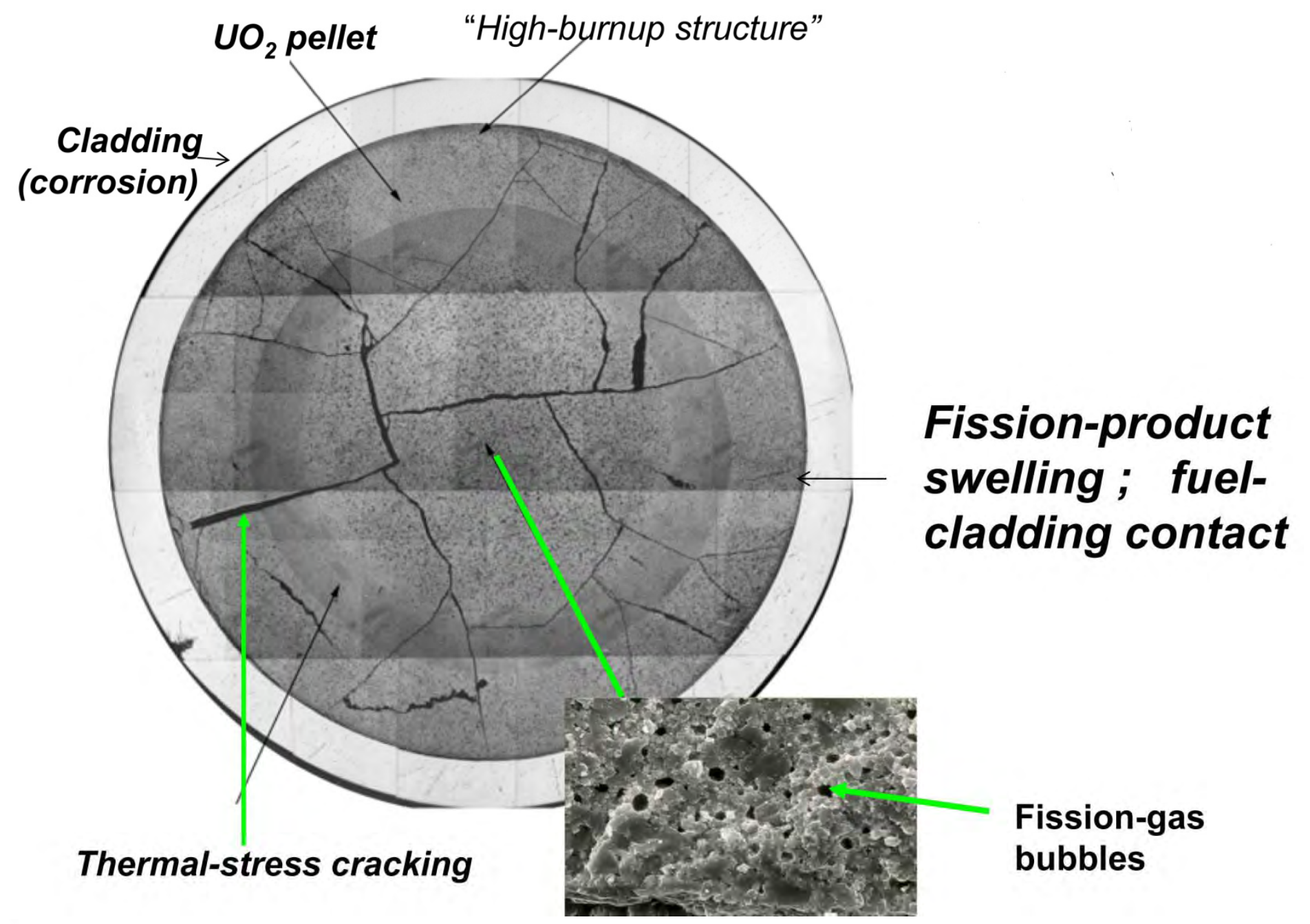




\section{Radiation Damage in ${ }^{244} \mathrm{Cm}$-doped $\mathrm{Ca}_{2} \mathrm{Ndl}_{8}\left(\mathrm{SiO}_{4}\right)_{6} \mathrm{O}_{2}$}

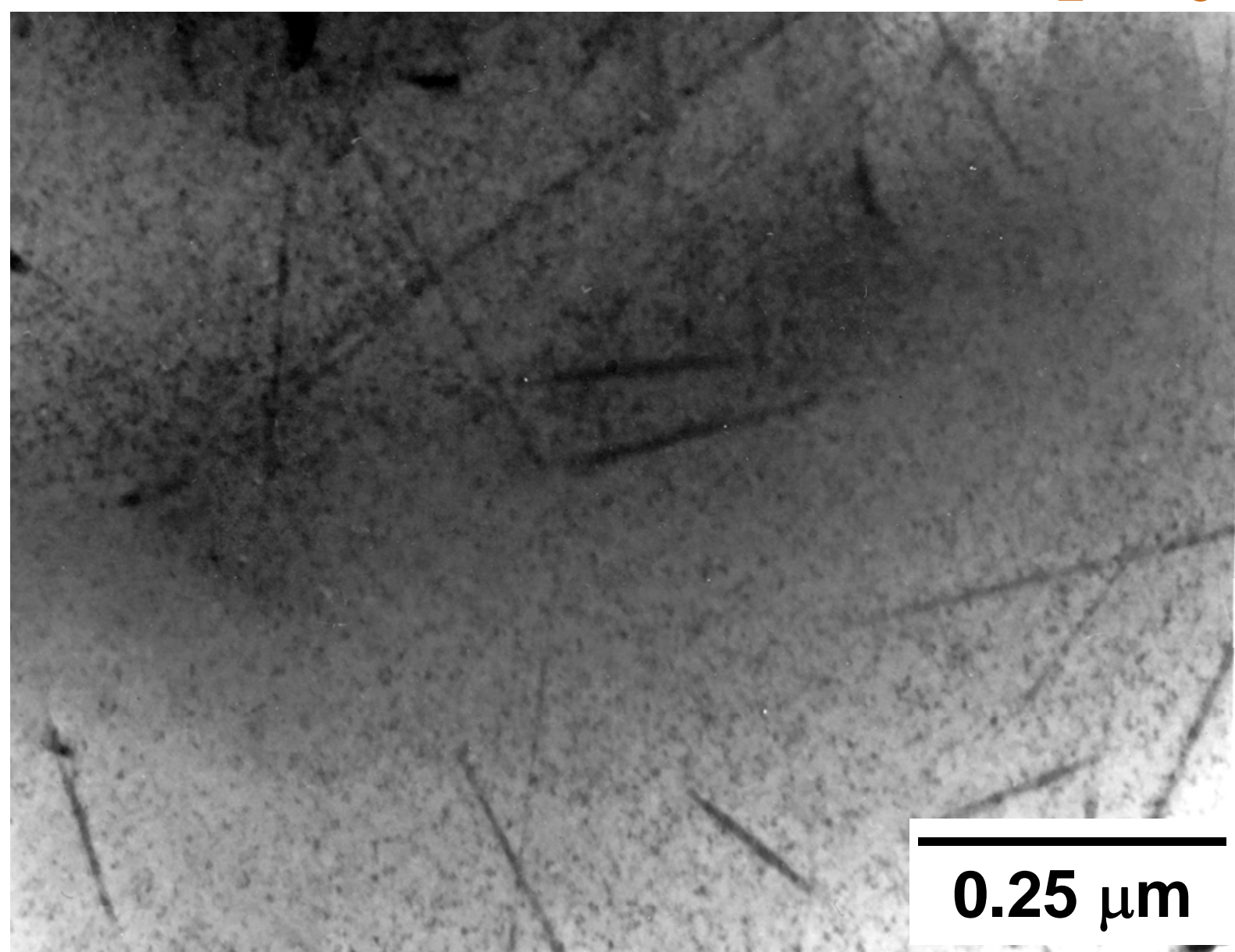

> Fission Tracks from Spontaneous Fission

$>$ Alpha-Recoil Tracks (95 keV ${ }^{240} \mathrm{Pu}$ ) from Alpha Decay 


\section{Studying Fission Damage with Swift-Heavy lons}

$>$ Nanoscale, Linear and Parallel Structures

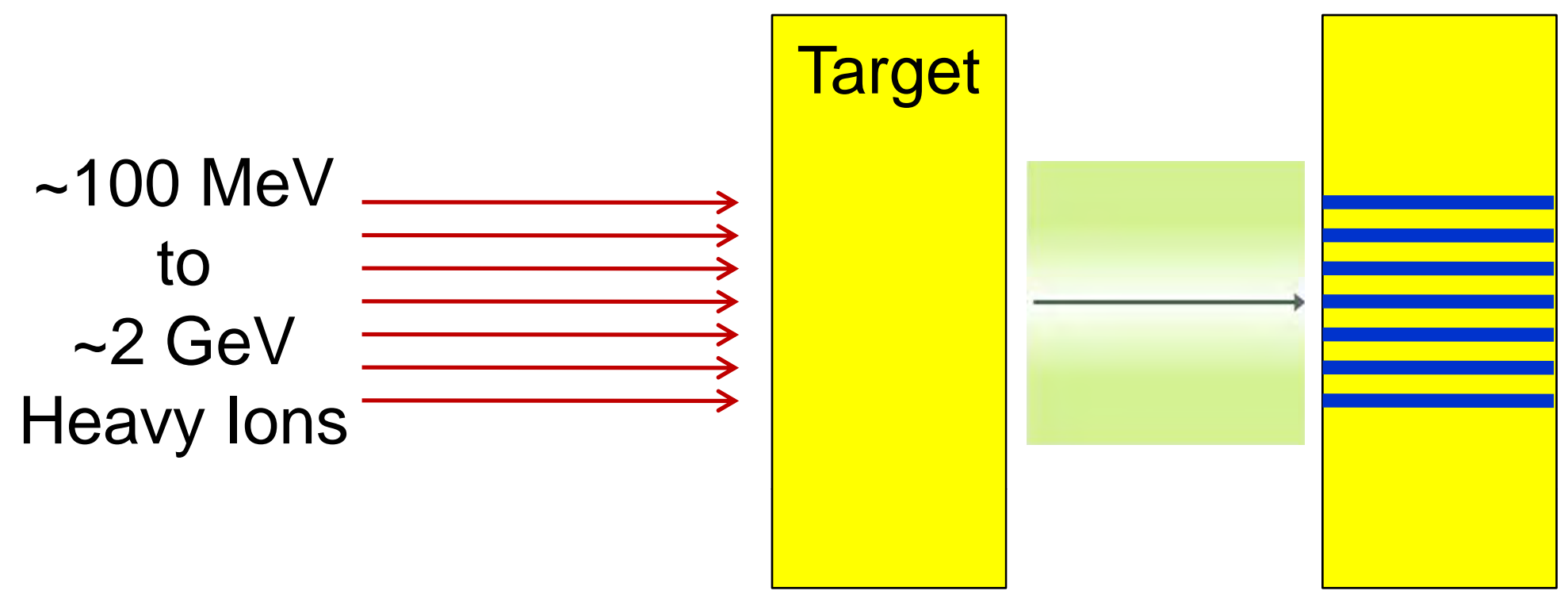

apatite

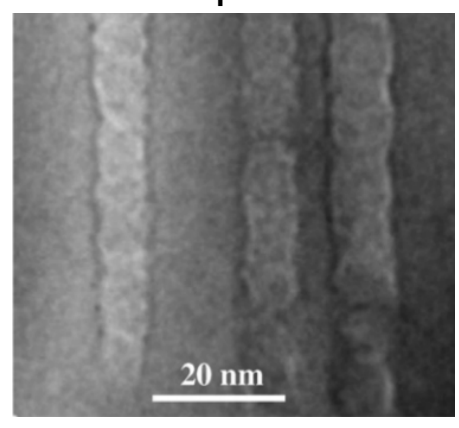

mica

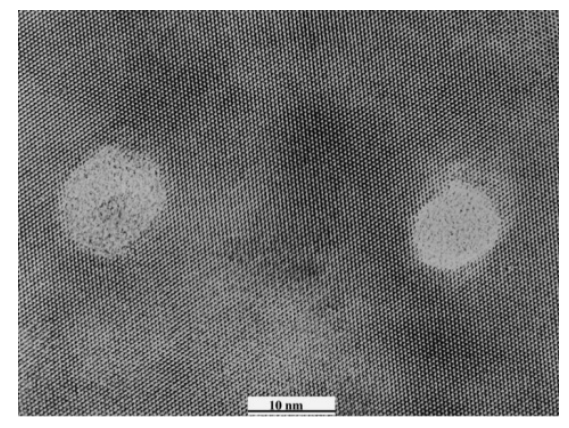

Leo A Kim et al., Neuron 41, 513 (2004)

Weixing Li et al., EPSL 302, 227 (2011) 


\section{Simulating Fission Tracks with Swift-Heavy Ions}

1.43 GeV Xe ${ }^{+}$Tracks in $\mathrm{Gd}_{2} \mathrm{Ti}_{\mathrm{x}} \mathrm{Zr}_{2-\mathrm{x}} \mathrm{O}_{7}$ Bright-Field TEM Images

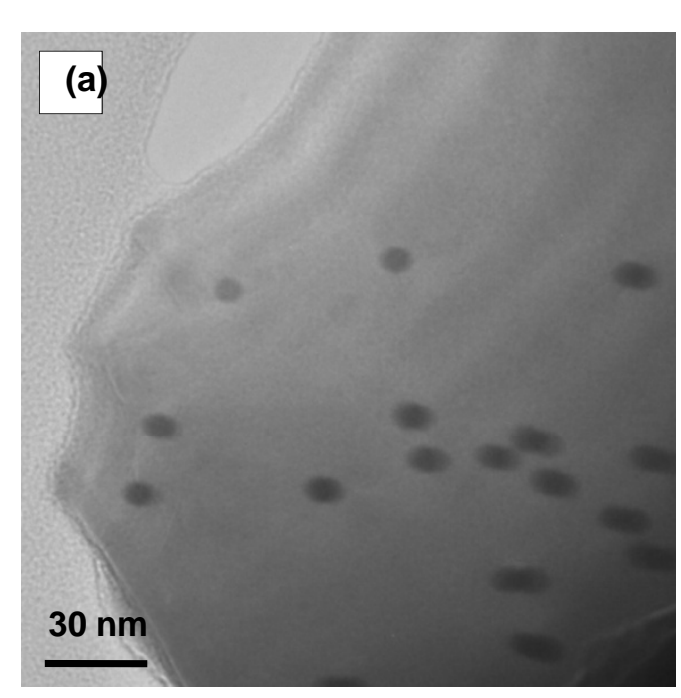

$\mathrm{Gd}_{2} \mathrm{Ti}_{2} \mathrm{O}_{7}$

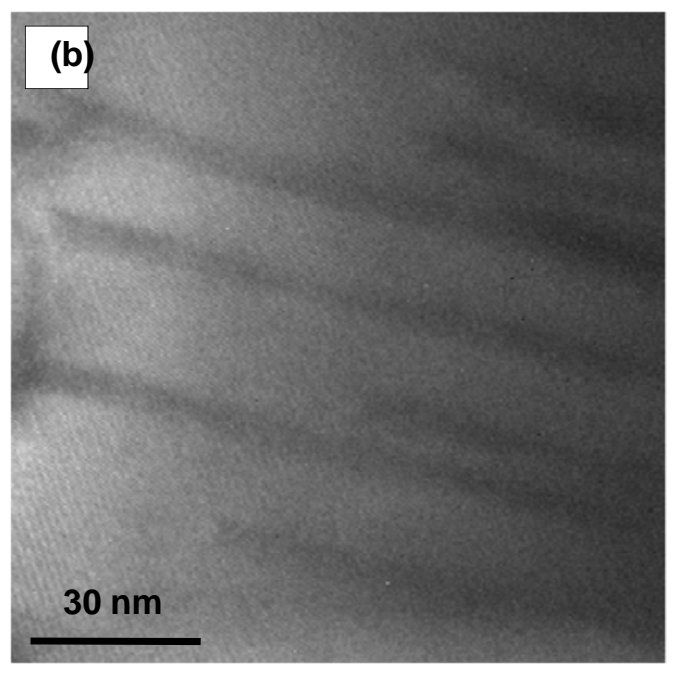

$\mathbf{G d}_{\mathbf{2}} \mathrm{TiZrO}_{\mathbf{7}}$

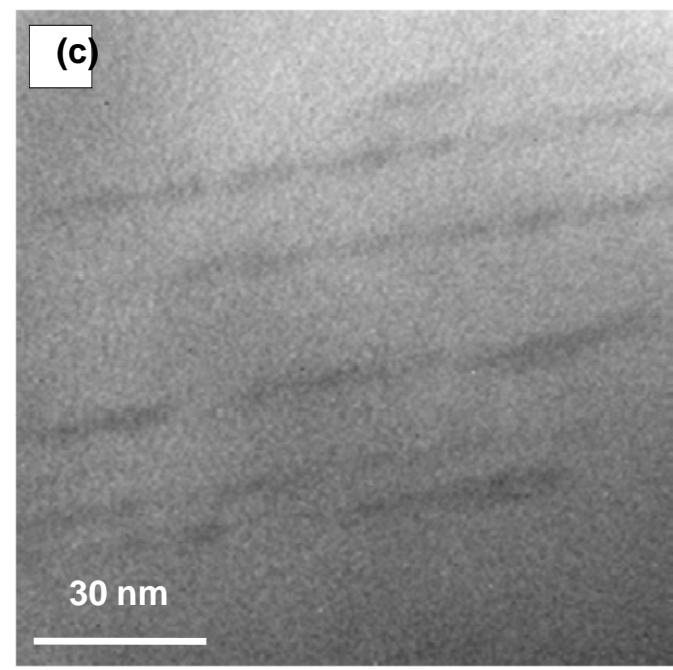

$\mathrm{Gd}_{2} \mathrm{Ti}_{0.5} \mathrm{Zr}_{1.5} \mathrm{O}_{7}$

Swift Heavy lons Tracks are similar to Fission Tracks 


\section{$1.43 \mathrm{GeV}$ Xe Track in $\mathrm{Gd}_{2} \mathrm{Ti}_{2} \mathrm{O}_{7}$}

\section{$\mathrm{dE} / \mathrm{dx}=28.5 \mathrm{keV} / \mathrm{nm}$}

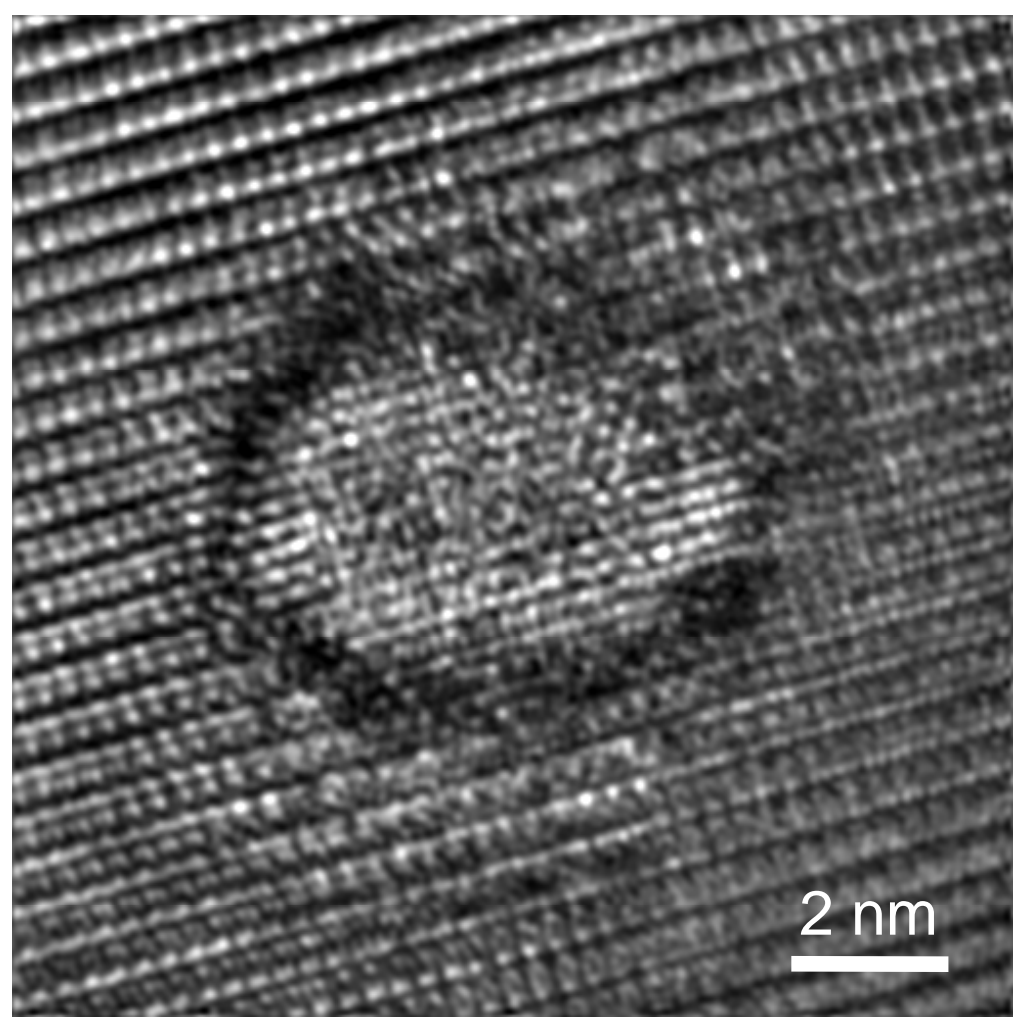

HRTEM Image

(M. Lang et al. Phys. Rev. B 79, 224105 (2009))

\section{$\mathrm{dE} / \mathrm{dx}=12 \mathrm{keV} / \mathrm{nm}$}

(No electron-phonon coupling efficiency)

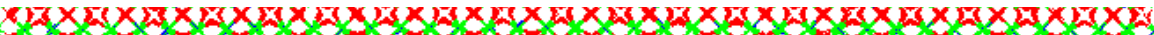

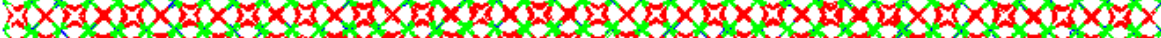

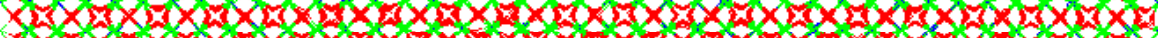

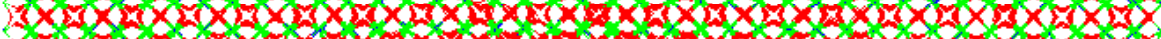

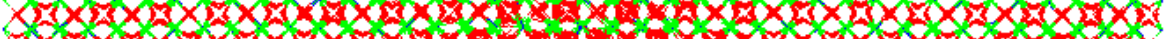

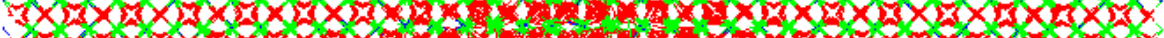

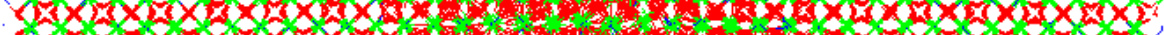

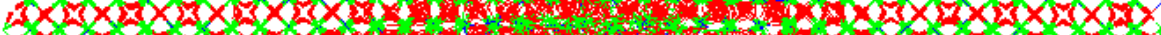

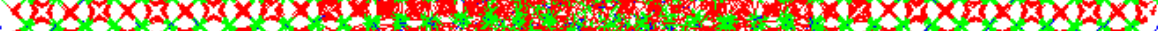

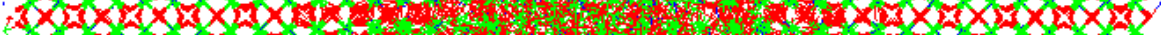

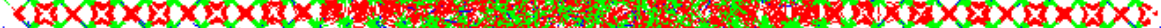

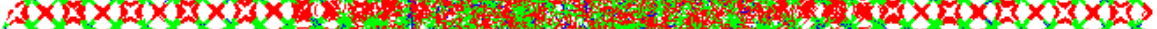

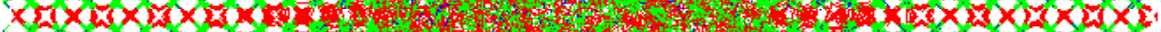

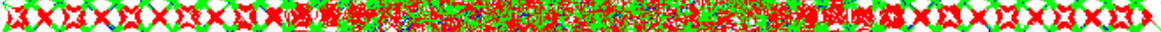

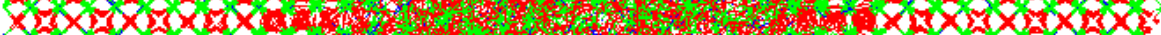
$\times \times \times \times 0 \times 0 \times \times$.

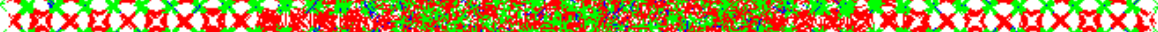

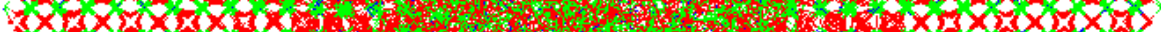

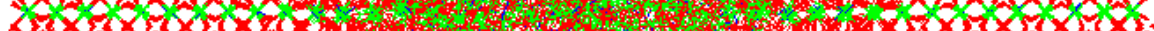
$0 \times 00000 \%$ \%

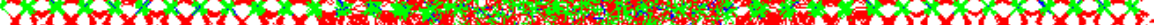

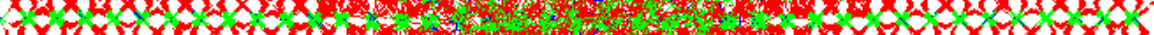

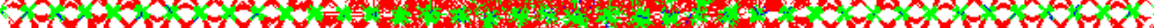

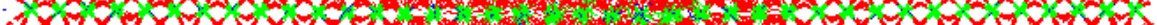

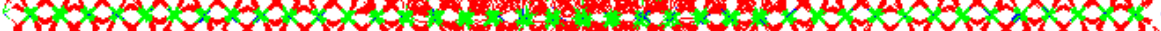

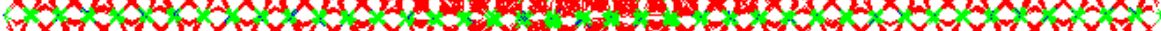

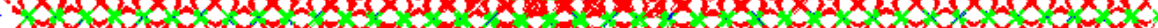

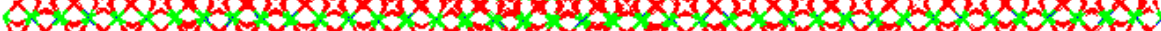

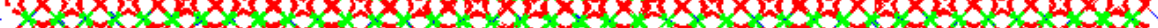

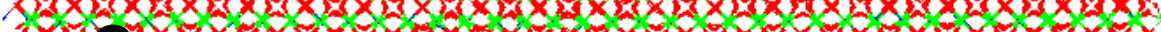

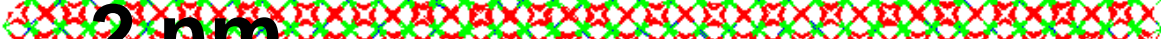

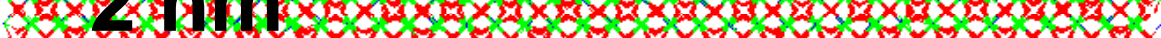

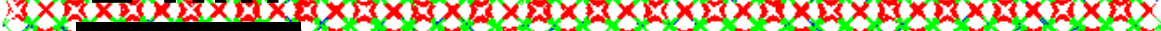

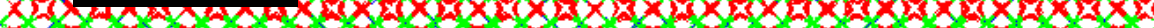

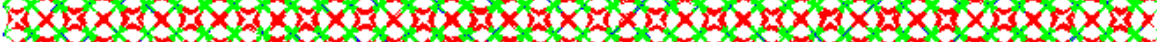

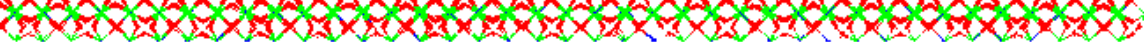

\section{Thermal Spike Simulation}

(J. Zhang et al., J. Mater. Res. 25, 1344 (2010))

OAK

RIDGE 


\section{Neutron Damage in Nuclear Reactors}

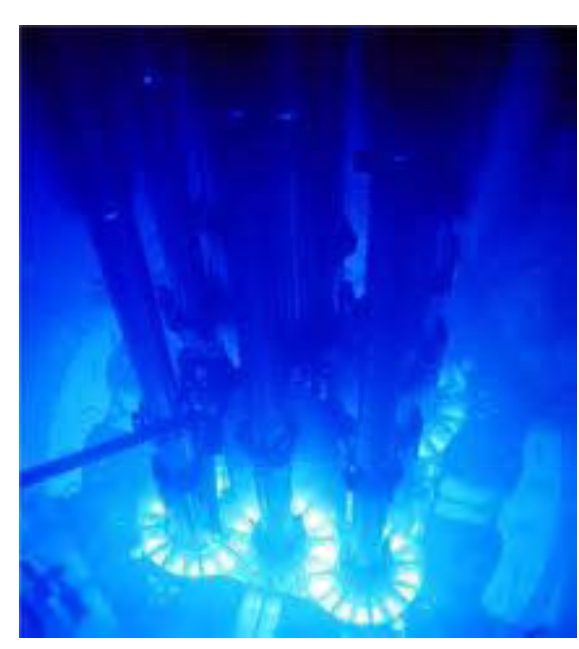

Core Components

Irradiation-Induced Growth

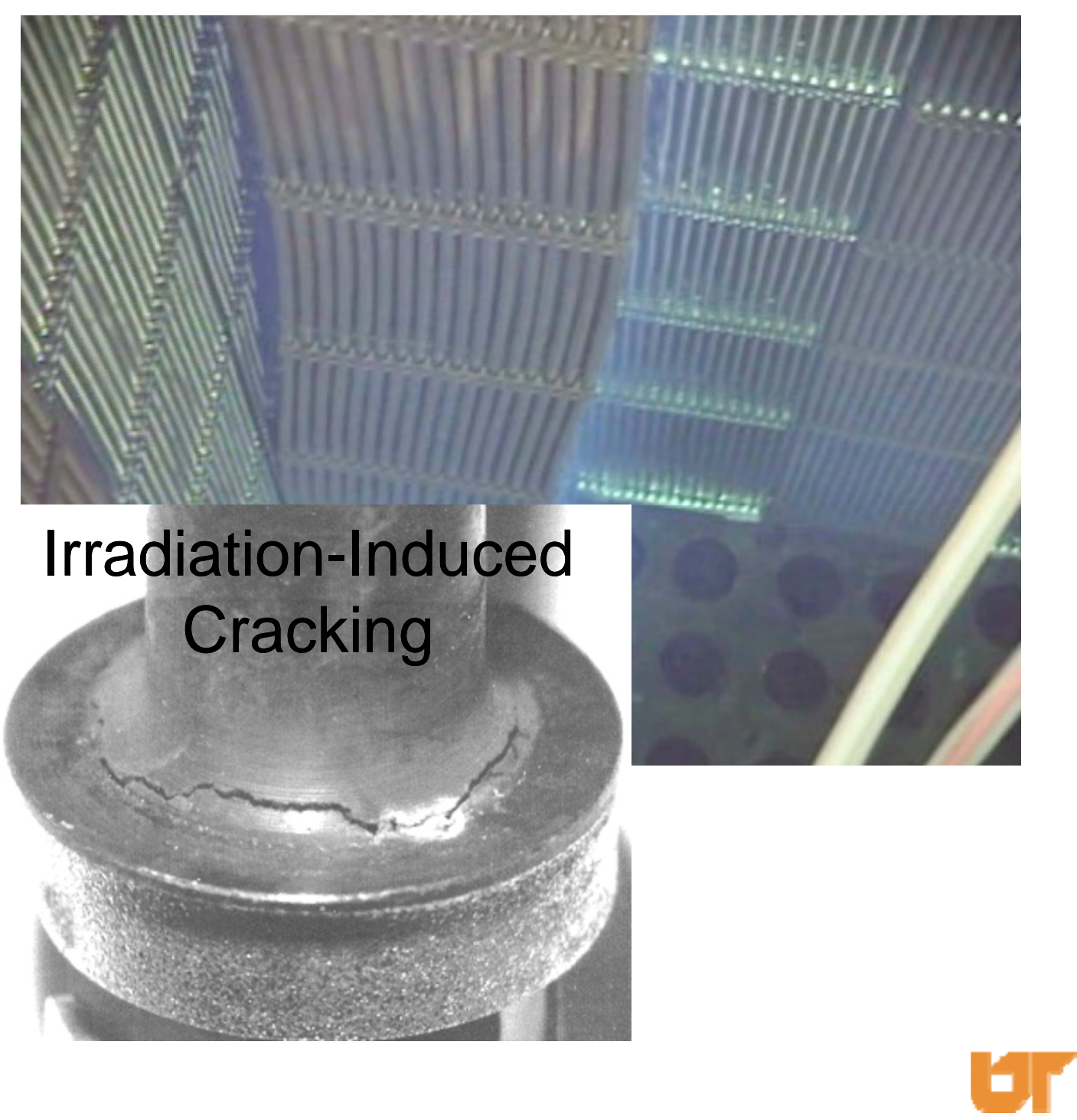




\section{Neutron Spectra vs Monoenergetic Ion Beam}

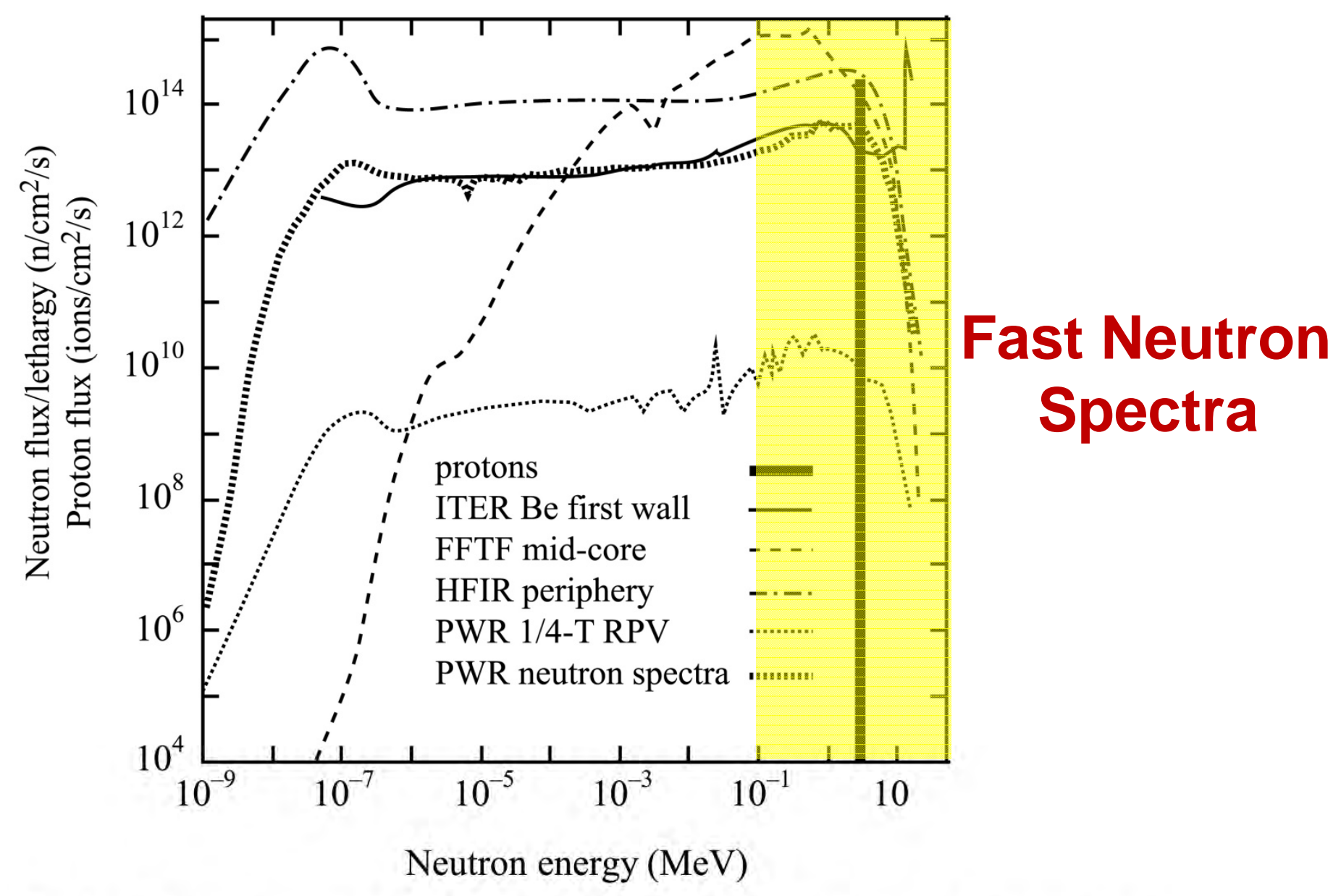

Fig. 11.1. Energy spectra of incident ions in a monoenergetic ion beam, and neutrons from a variety of reactor types (from [7]) 


\section{Thermal \& Fast Neutron Irradiation}

\section{Other Considerations}

$>$ Production of Helium and Hydrogen from $(n, \alpha)$ and $(n, p)$ nuclear reactions

- Promotes void and bubble formation

$>$ Accumulation of Transmutation and Decay Products (changes in chemistry of materials)

$>$ Accumulation of Helium, Hydrogen, and Transmutation/Decay Products can be simulated to some extent with Multiple Ion Beams 


\section{Protons vs Neutrons: GB Segregation}

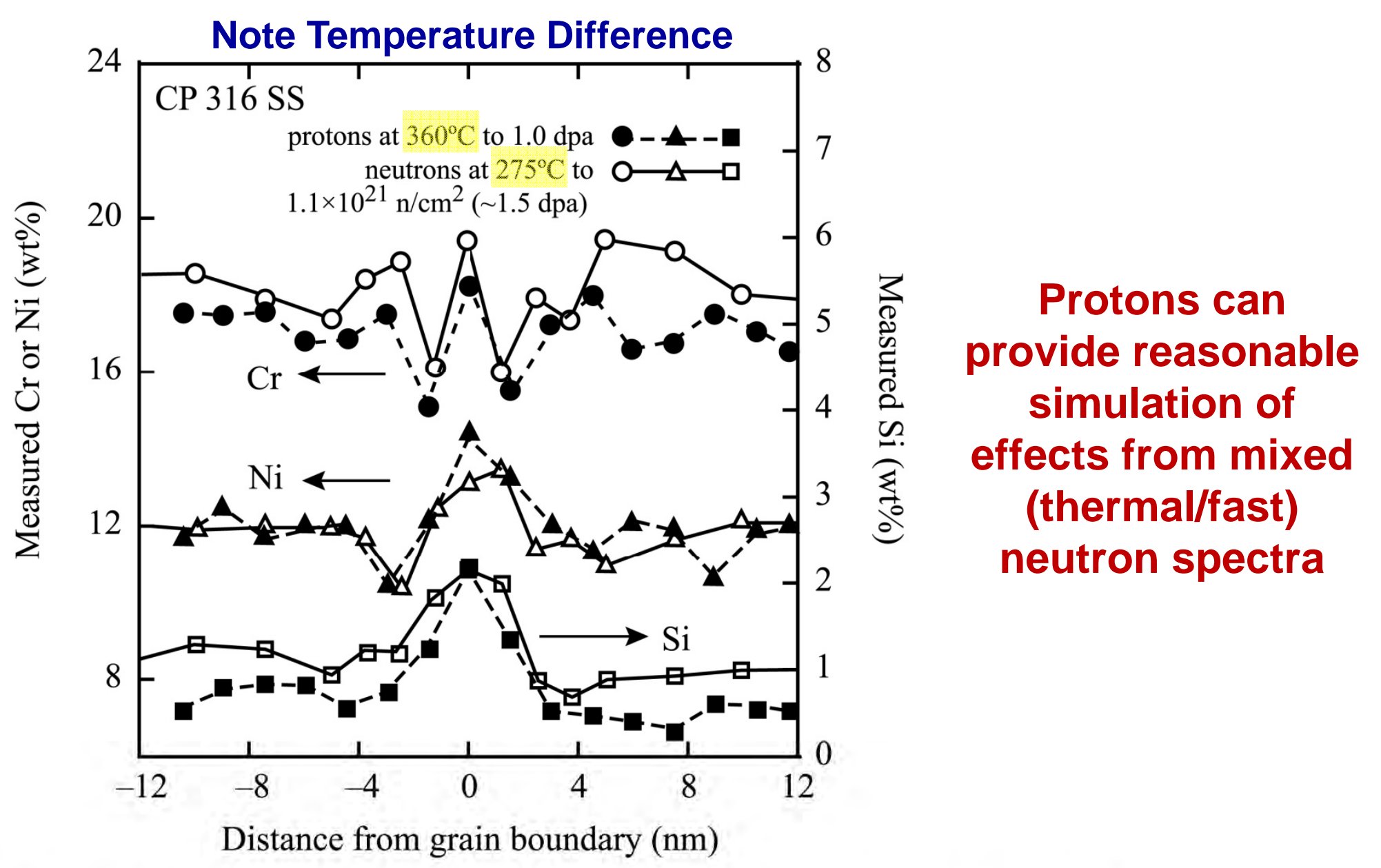

Fig. 11.18. Comparison of grain boundary segregation of $\mathrm{Cr}, \mathrm{Ni}$ and $\mathrm{Si}$ in commercial purity 316 stainless steel following irradiation with either protons or neutrons to similar doses (from [21]) 


\section{Protons vs Neutrons: Loop Formation}

\section{Note Temperature Difference}
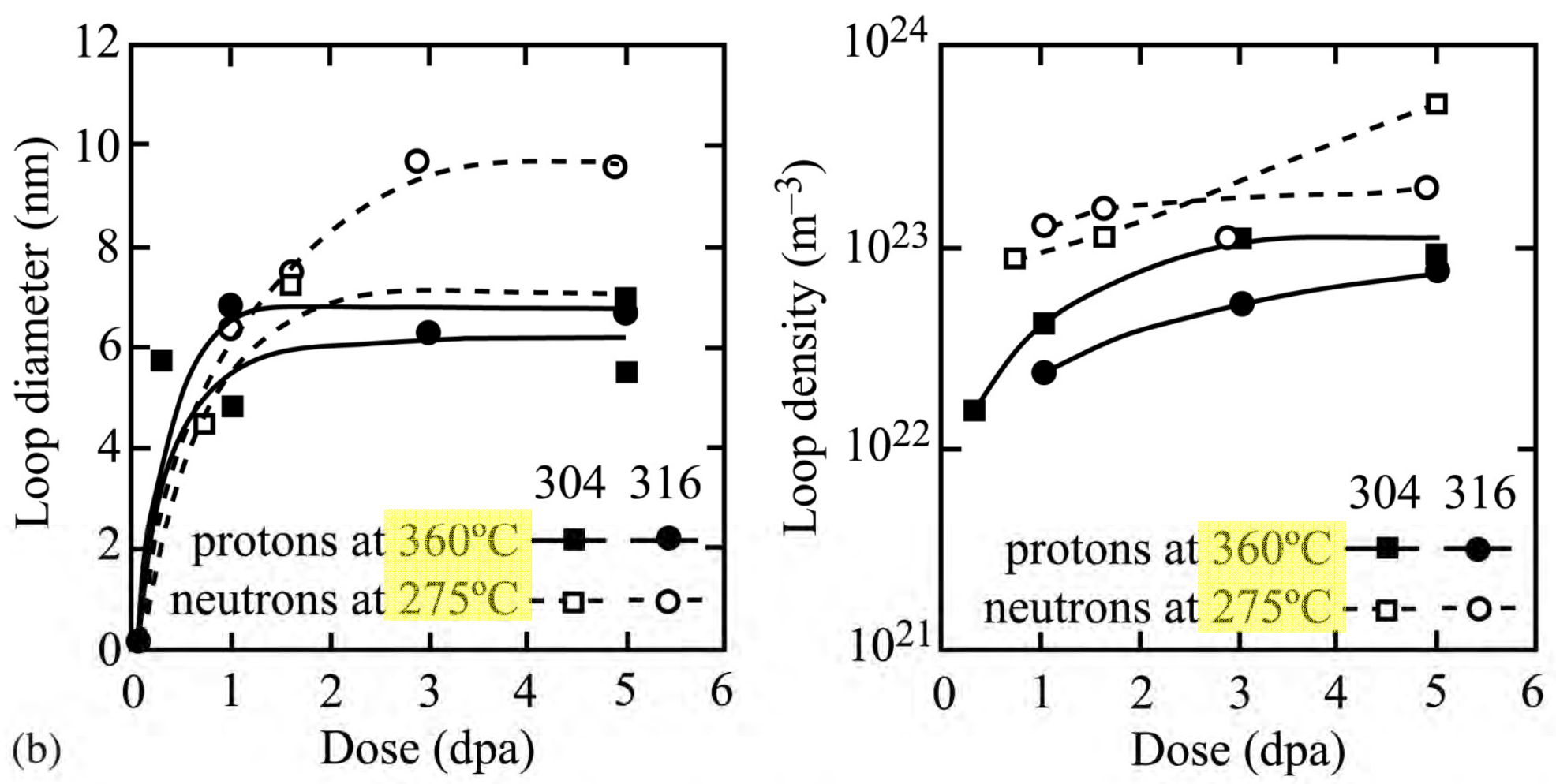

Fig. 11.19. Comparison of (a) loop size distributions and (b) loop diameter and loop number density for commercial purity 304 and 316 stainless steels irradiated with neutrons or protons to similar doses (from [21]) 


\section{Fast Neutron Damage}




\section{Radiation Damage from Fast Neutrons}

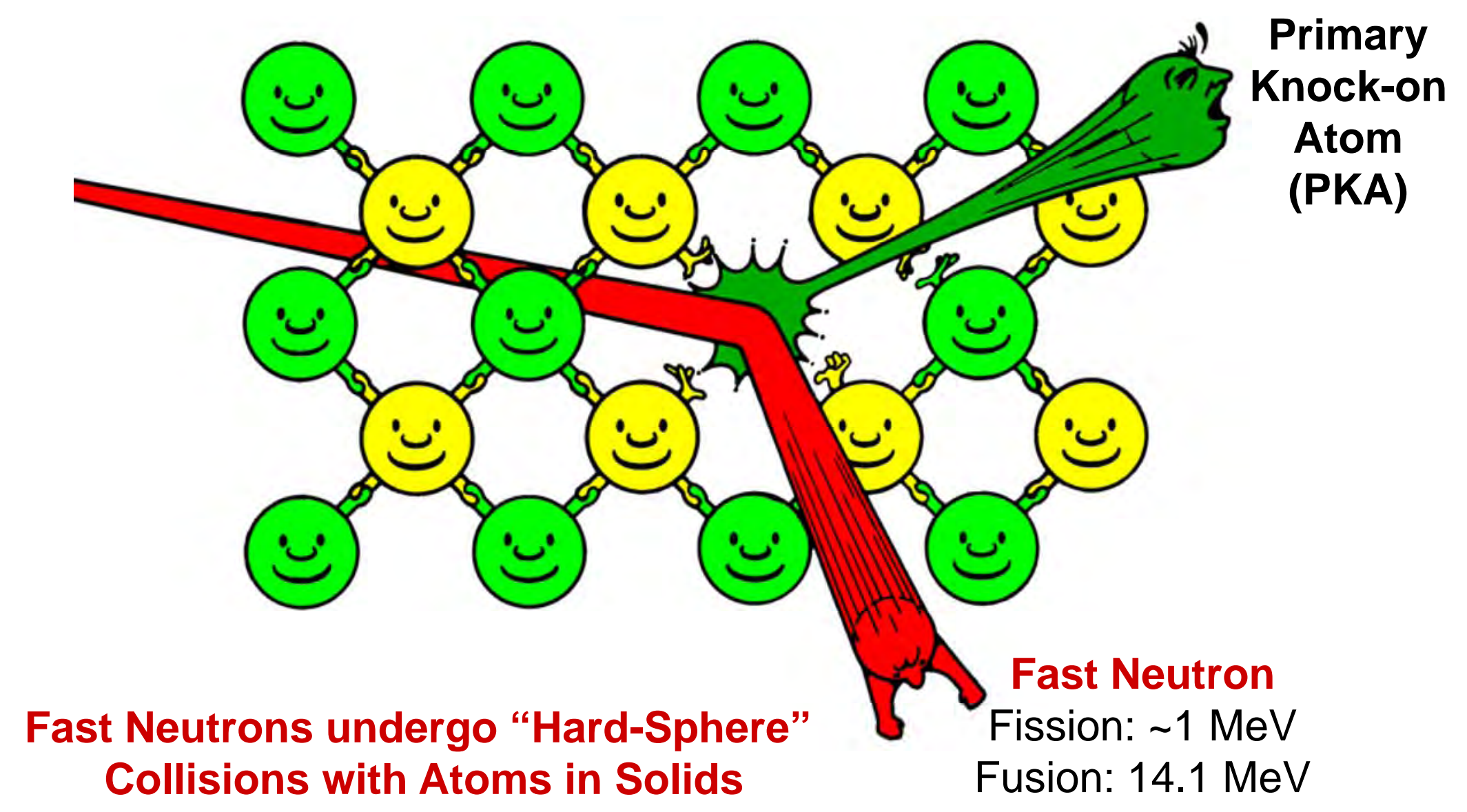

> Fission PKAs: 50 to $300 \mathrm{keV}$ lons

$>$ Fusion PKAs: up to several MeV lons 


\section{Defect Microstructures in Irradiated Materials}

Voids,

Point defect

accumulation

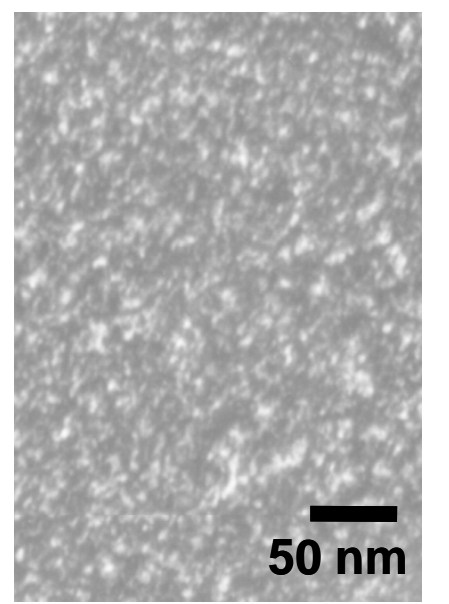

Dislocation

loop formation

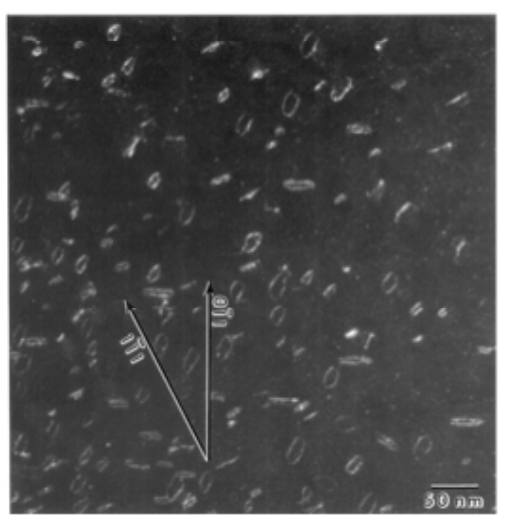

precipitates, solute segregation

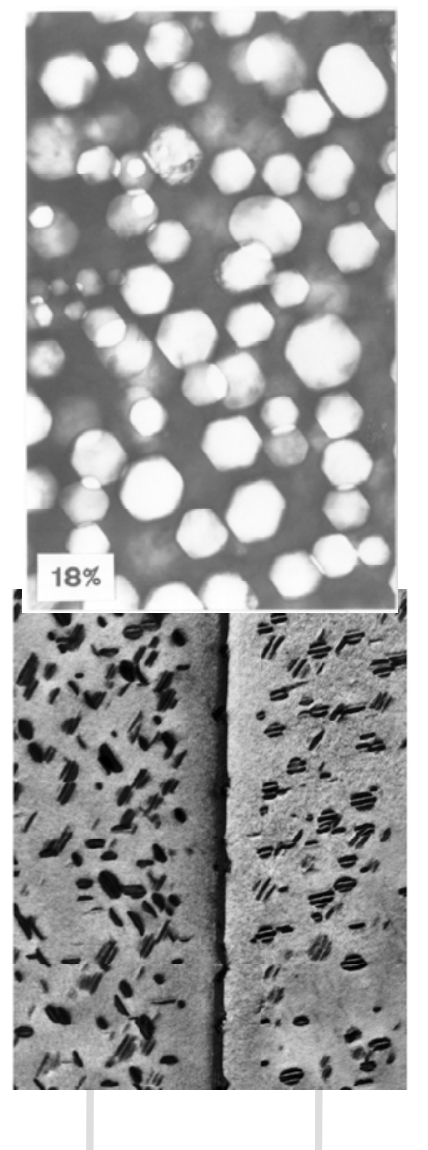

0.3

0.4

Helium bubbles (grain boundaries)
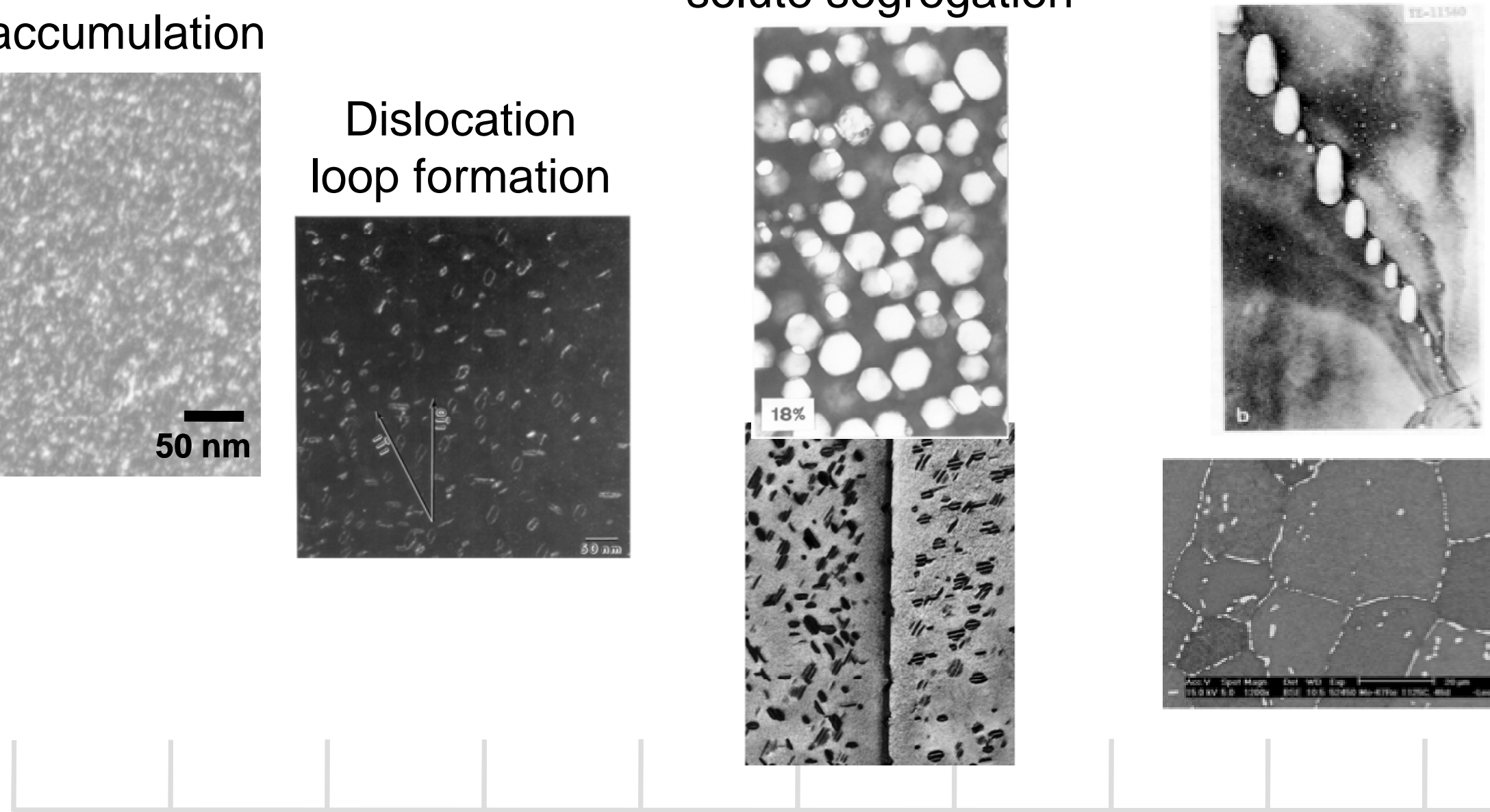

0.2 Irradiation Temperature $\left(\mathrm{T} / \mathrm{T}_{\mathrm{M}}\right)$

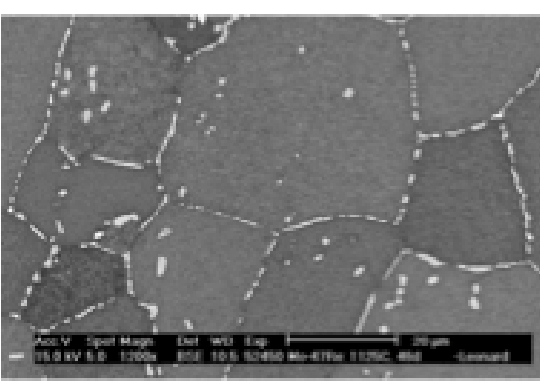

0.5

0.6

\begin{tabular}{cc|}
0.3 & 0.4 \\
Irradiation Temperature $\left(\mathrm{T} / \mathrm{T}_{\mathrm{M}}\right)$
\end{tabular}

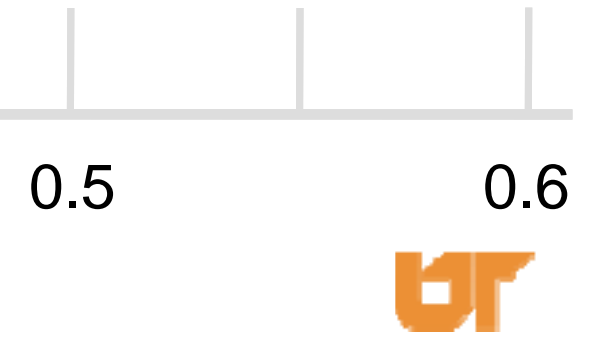




\section{Swelling Changes due to Temperature \& Dose (Neutron Irradiation)}

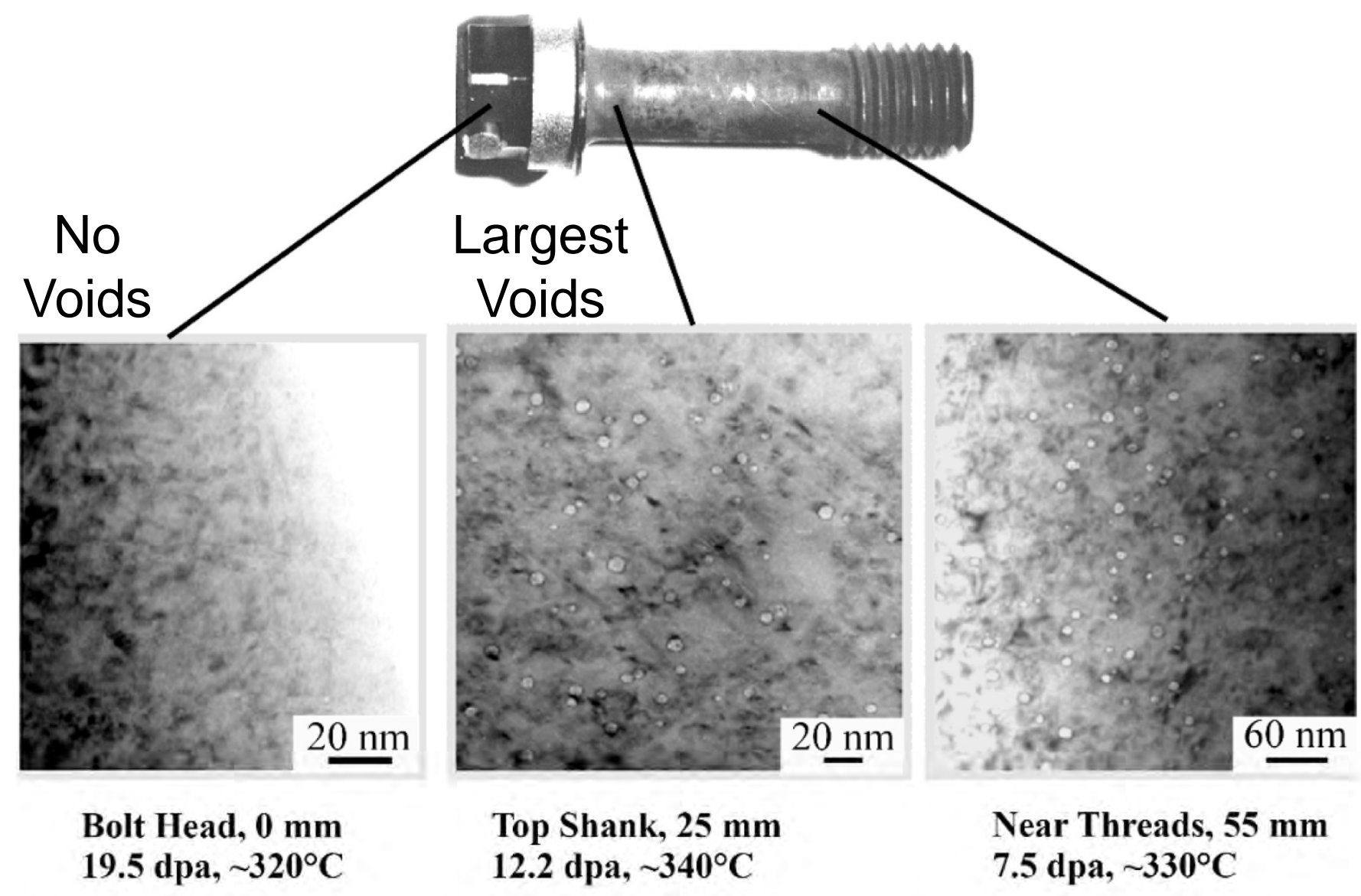

Fig. 8.19. Swelling in a cold-worked 316 SS baffle bolt in a PWR as a function of position along the bolt length. The bolt head was closest to the core and the temperature distribution is caused by a combination of gamma heating and whether the bolt was exposed to the coolant (courtesy S.M. Bruemmer and Garner FA, PNNL) 


\section{Temperature Shift of Void Growth Rate with Dose Rate}

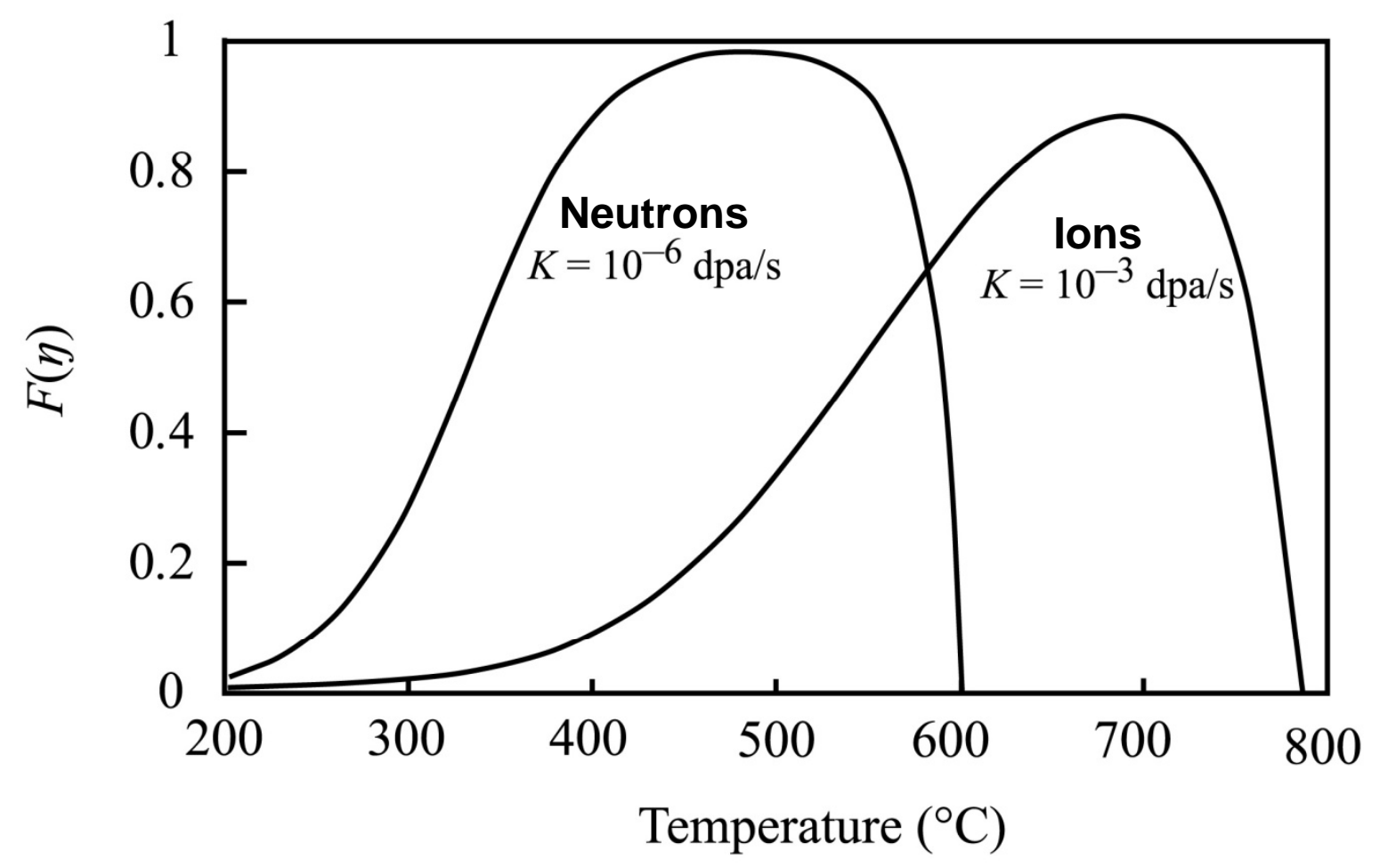

Fig. 8.24. Variation of the function $F(\eta)$ in Eq. (8.124) with temperature, illustrating the shift of the peak with dose rate, $K_{0}$. Parameters used to construct the curves are as follows: $\rho_{\mathrm{d}}=10^{9} \mathrm{~cm}^{-2}, E_{\mathrm{f}}^{\mathrm{v}}=1.6 \mathrm{eV}, z_{\mathrm{i}}-z_{\mathrm{v}}=0.01, z_{\mathrm{v}}=1,4 \pi R \rho_{\mathrm{V}}=10^{-11} \mathrm{~cm}^{-2}, D_{\mathrm{v}}=$ $\exp (-1.4 \mathrm{eV} / k T) \mathrm{cm}^{2} \mathrm{~s}^{-1}$ (after [15]) 


\section{Void Free Regions \& Void Size/Density Changes near Grain Boundaries in neutron-irradiated Cu}

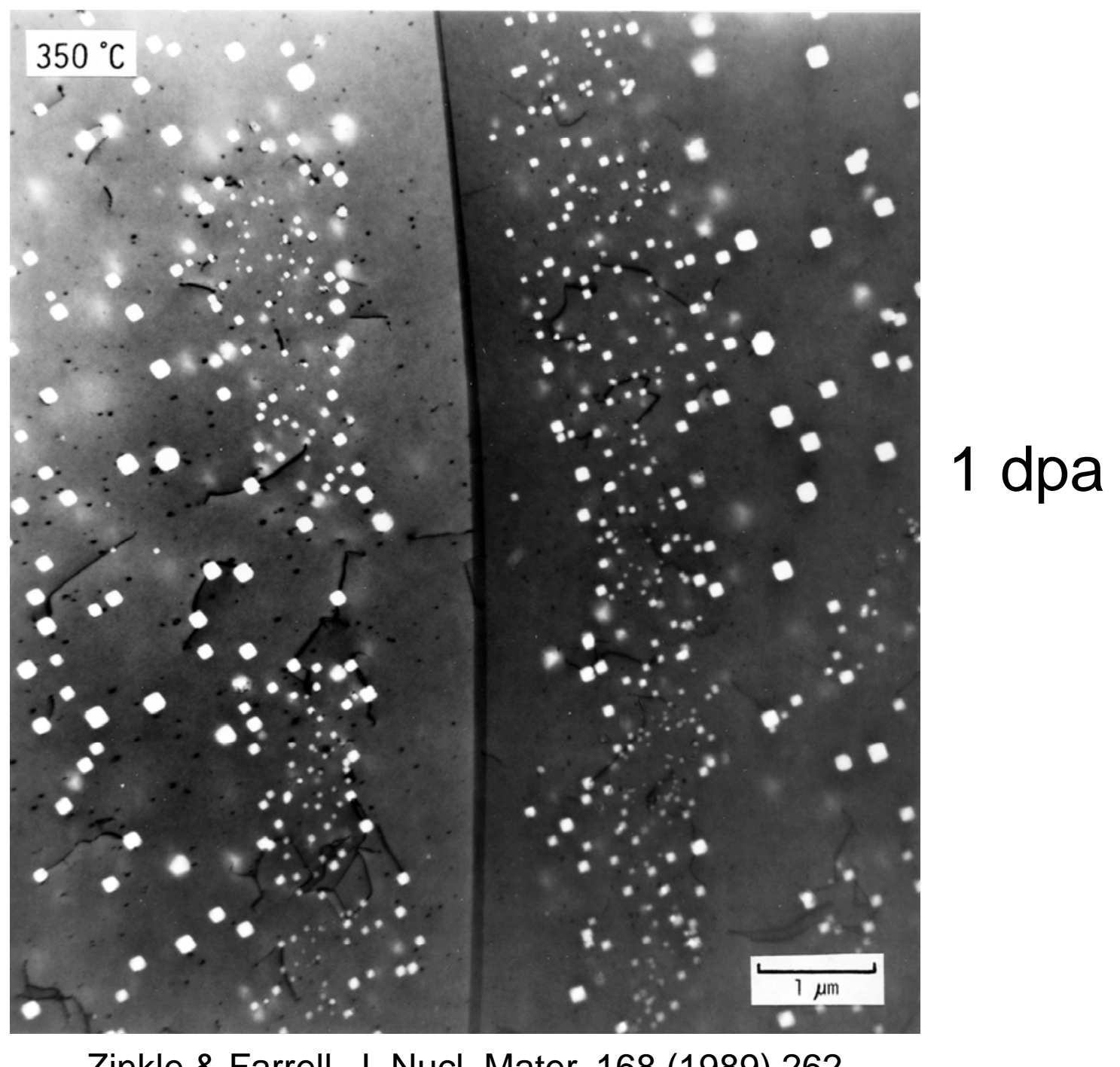




\section{Effect of Grain Boundaries in Vanadium Ion Irradiated at $500^{\circ} \mathrm{C}$ to $1 \mathrm{dpa}$}

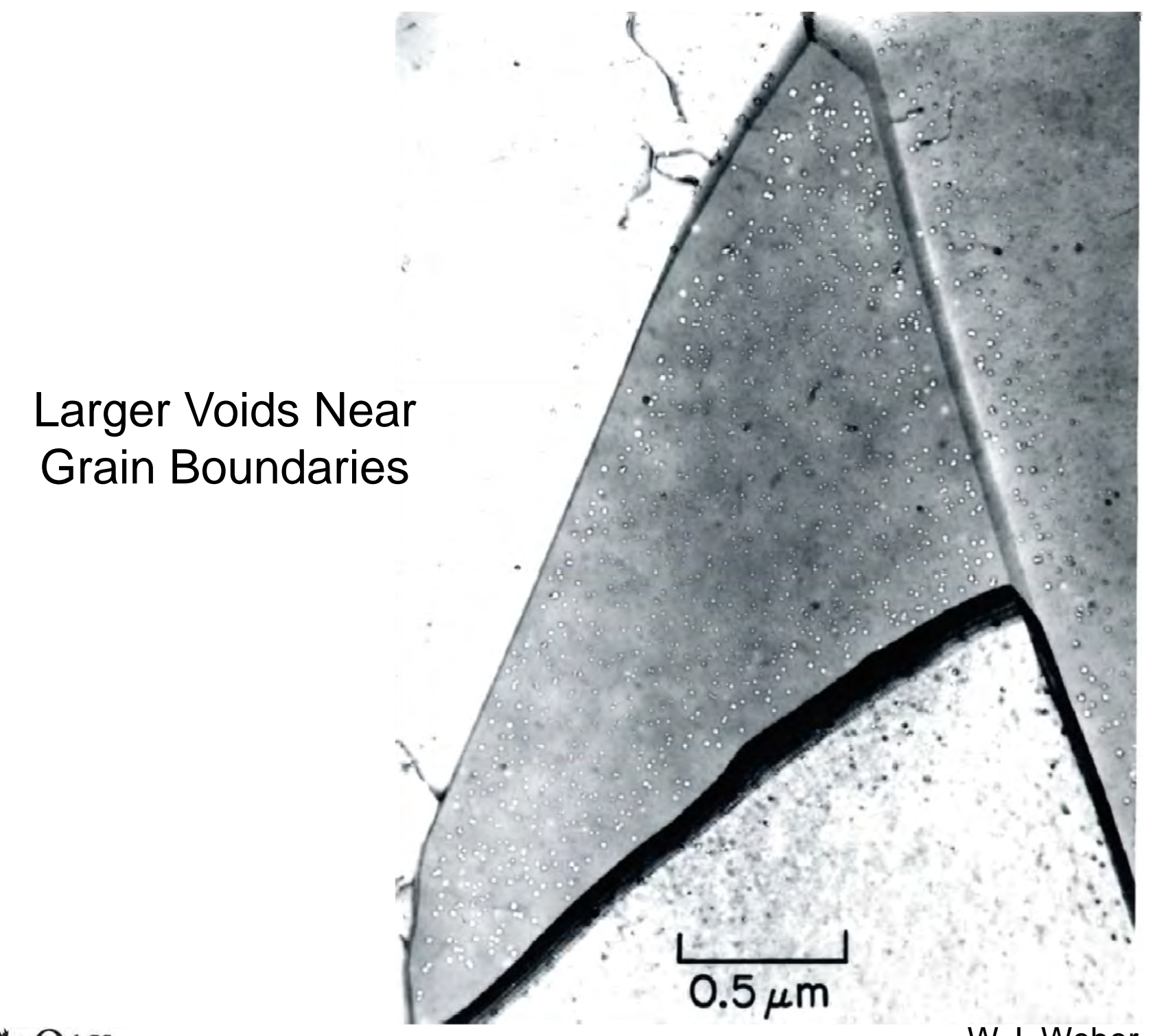




\section{Void and Helium Bubble Lattices}

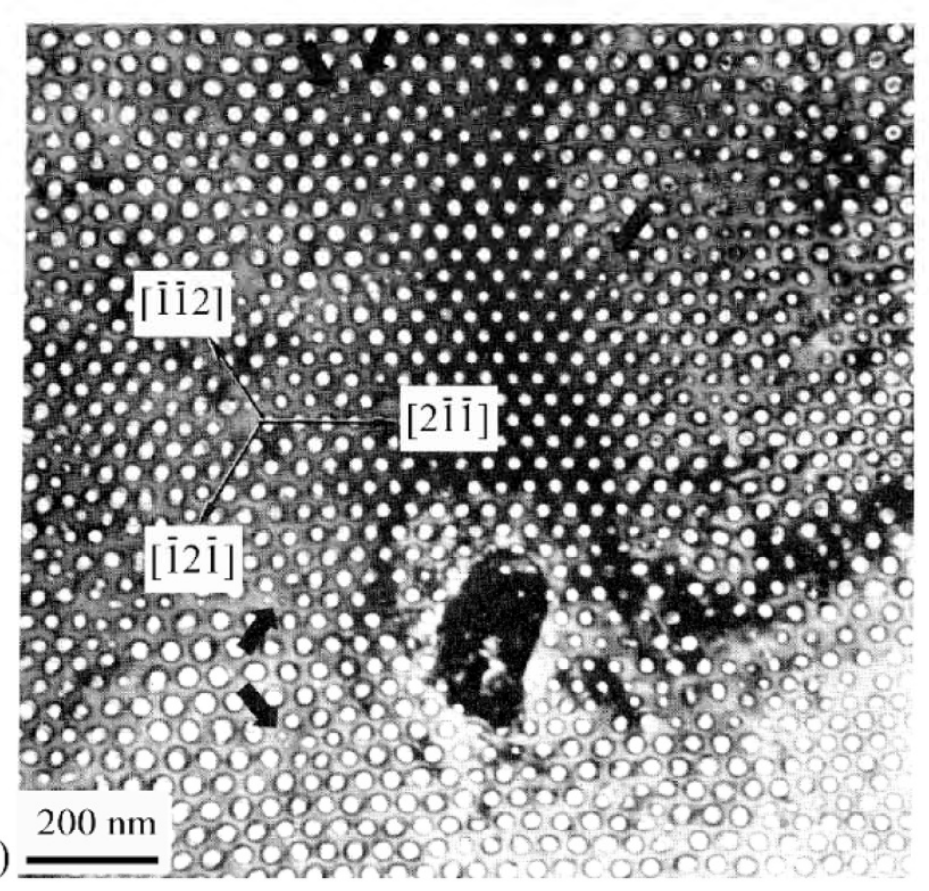

(a)

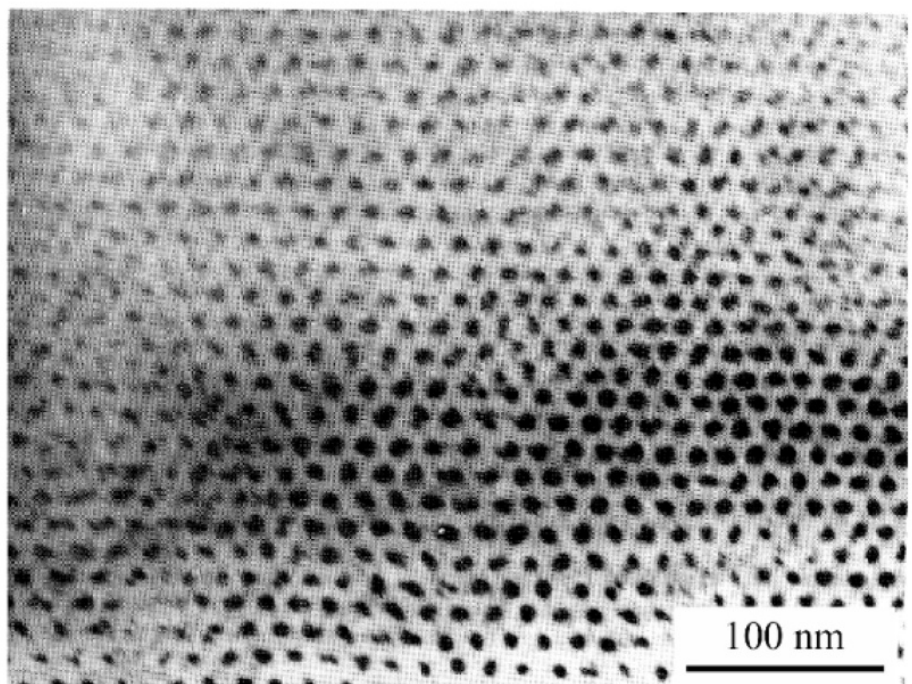

Fig. 8.39. Void lattice in (a) $\mathrm{Nb}$ irradiated with $8.5 \mathrm{MeV} \mathrm{Ta}^{+}$ at $800^{\circ} \mathrm{C}$ to $300 \mathrm{dpa}$, and helium bubble lattice in (b) Mo irradiated with $2 \mathrm{MeV} \mathrm{N}^{+}$ions to a dose of $100 \mathrm{dpa}$ at $870^{\circ} \mathrm{C}$ (after [39])

\section{3-D Void Lattice in Nb}

\section{3-D Bubble Lattice in Mo}

\section{G.S. Was, Fundamentals of Radiation
Materials Science (Springer, 2007) \\ G.S. Was, Fundamentals of Radiation
Materials Science (Springer, 2007)}

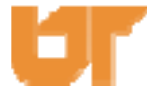




\section{Weighted Recoil Spectra for Ions in Ni}

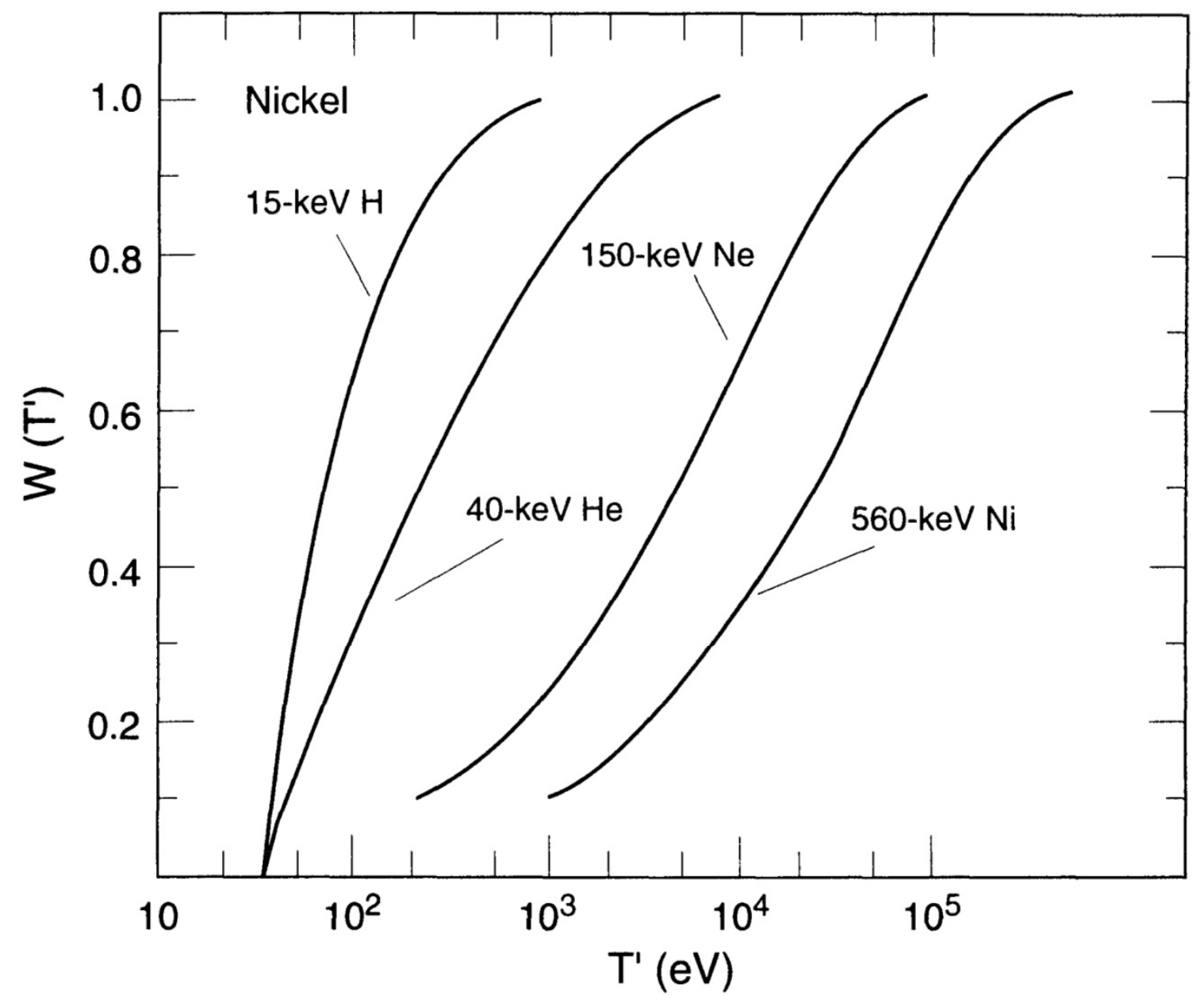

$W(T)=$ Fraction of defects produced by recoils of energy less than $T$ 


\section{Weighted Recoil Spectra for 1 MeV Particles in Cu}

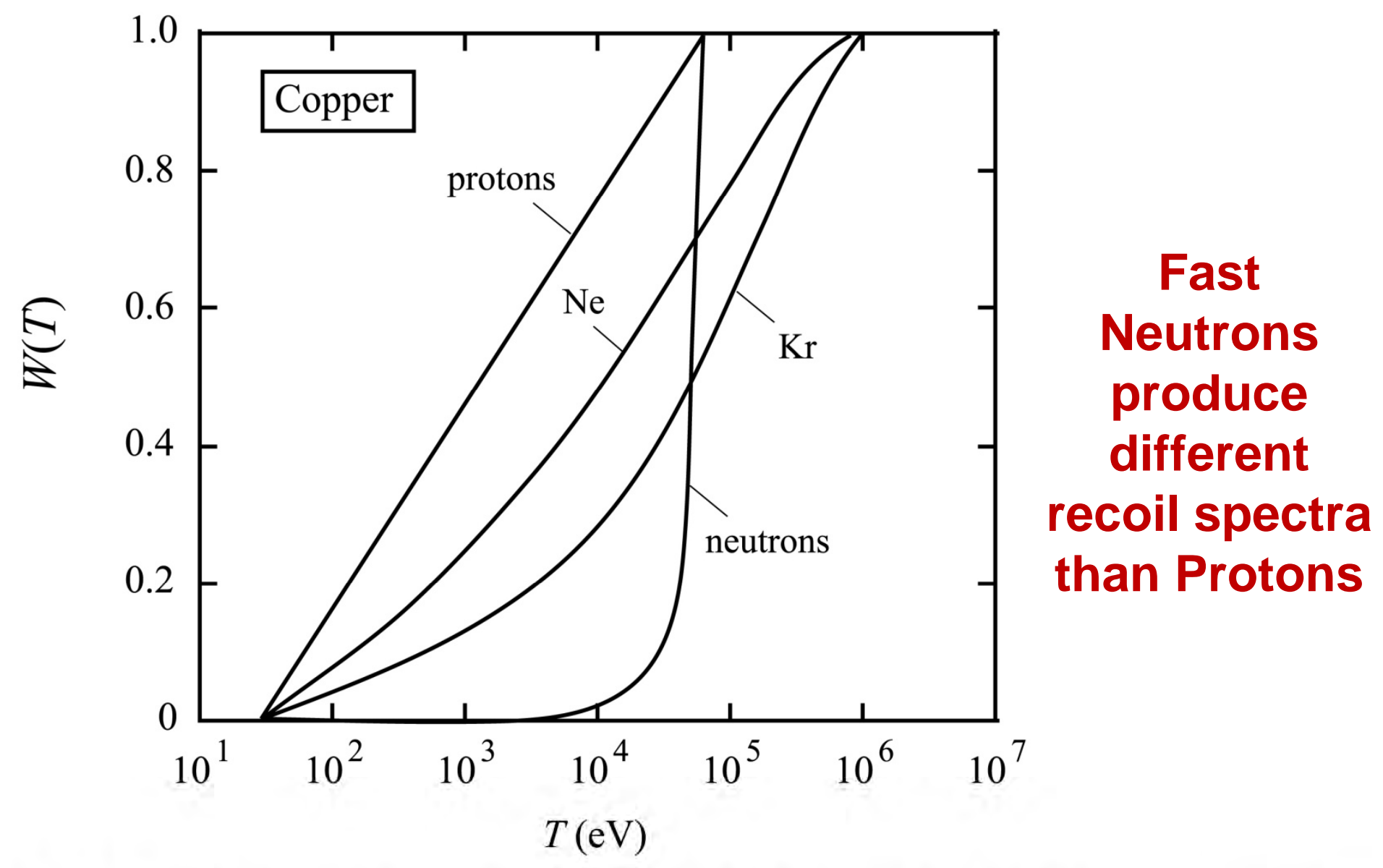

Fig. 3.6. Weighted recoil spectra for $1 \mathrm{MeV}$ particles in copper, (after [2]). Curves representing protons and neutrons are calculated using Eqs. (3.14) and (3.15), respectively. $W(T)$ for other particles were calculated using Lindhard cross sections and include electronic excitation 


\section{Comparison of Damage from $1 \mathrm{MeV}$ Particles in Ni}

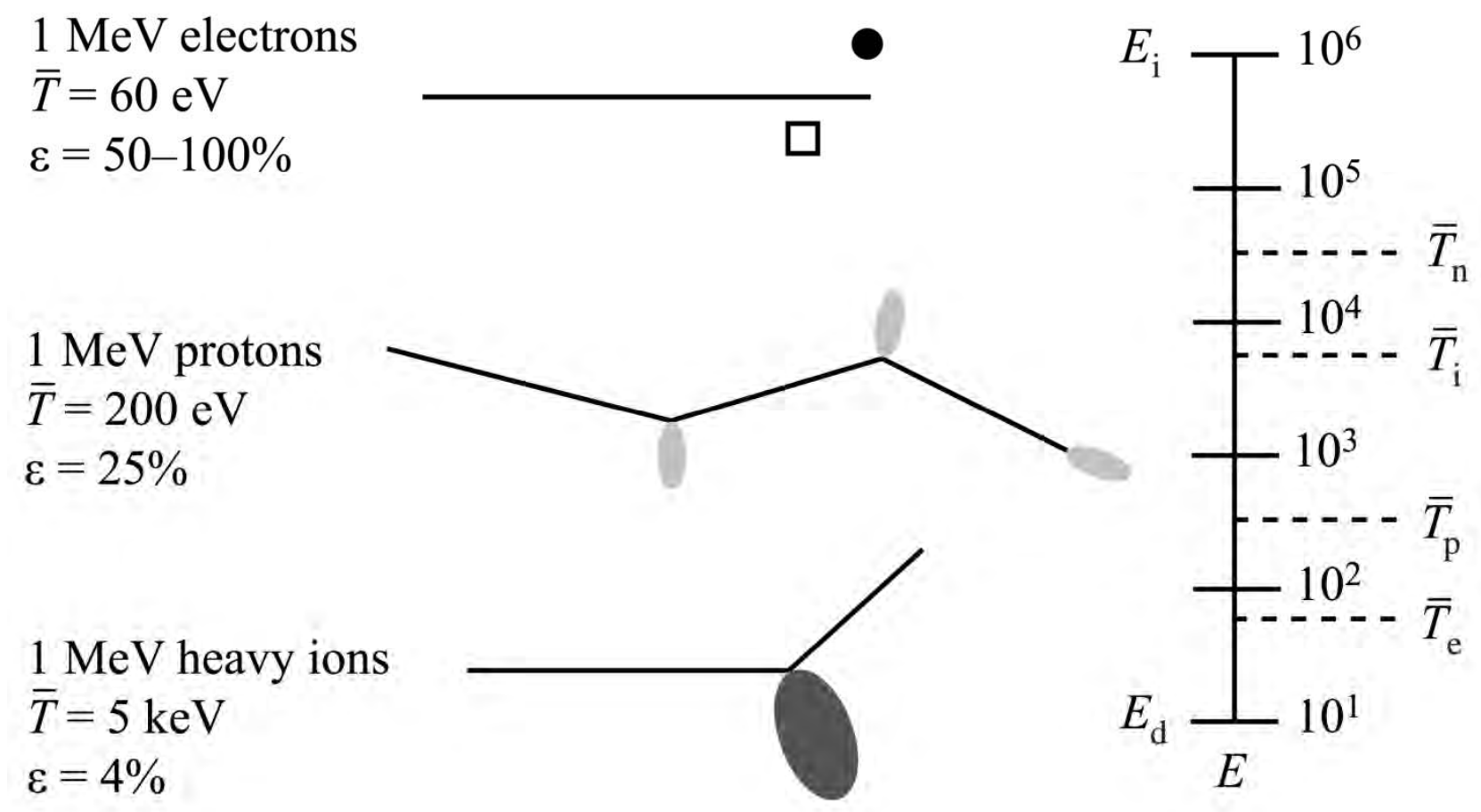

$1 \mathrm{MeV}$ neutrons

$\bar{T}=35 \mathrm{keV}$

$\varepsilon=2 \%$

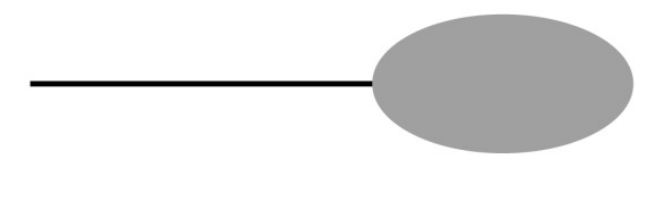




\section{Alpha-Decay Damage}




\section{Alpha-Decay Damage in Materials}

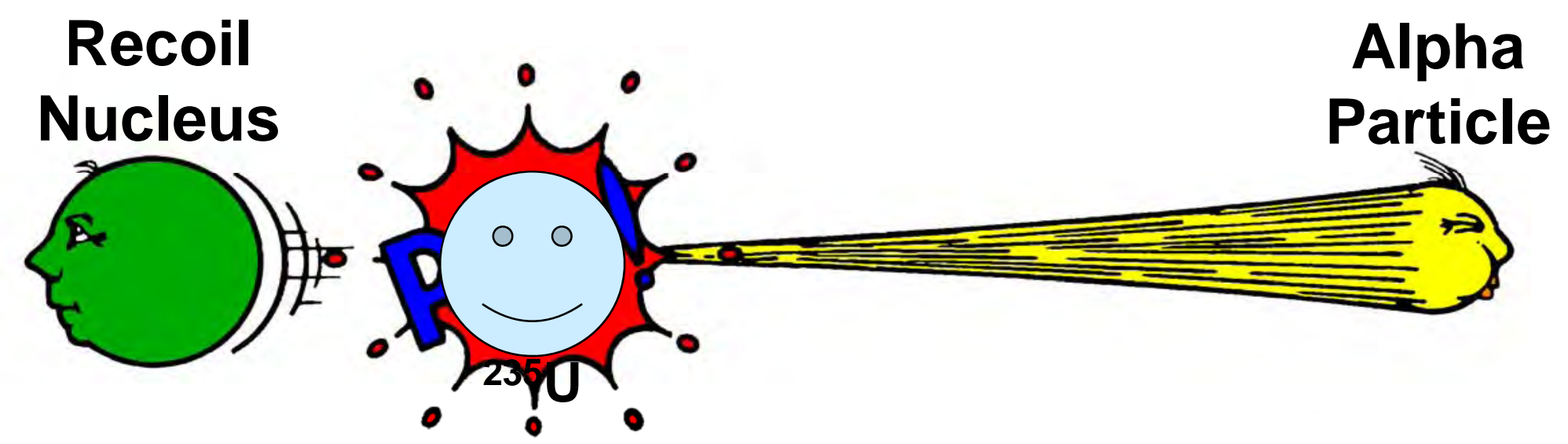

\section{Alpha-Recoil Nucleus}

$>70-100 \mathrm{keV}$ ions

$>30-40 \mathrm{~nm}$ Range

$>$ Creates More Damage ( 2000 Displaced Atoms)

\section{Alpha-Particle}

$>4.5-5.8 \mathrm{MeV}$ ions

$>16-22 \mu \mathrm{m}$ Range

$>$ Creates Less Damage ( 350 Displaced Atoms)

$>$ Atomic Collision Damage from Recoil Nucleus and Alpha Particle (both are energetic ions)

$>$ Helium accumulation 


\section{Self-Radiation Damage in ${ }^{244} \mathrm{Cm}$-doped $\mathrm{Gd}_{2} \mathrm{Ti}_{2} \mathrm{O}_{7}$}

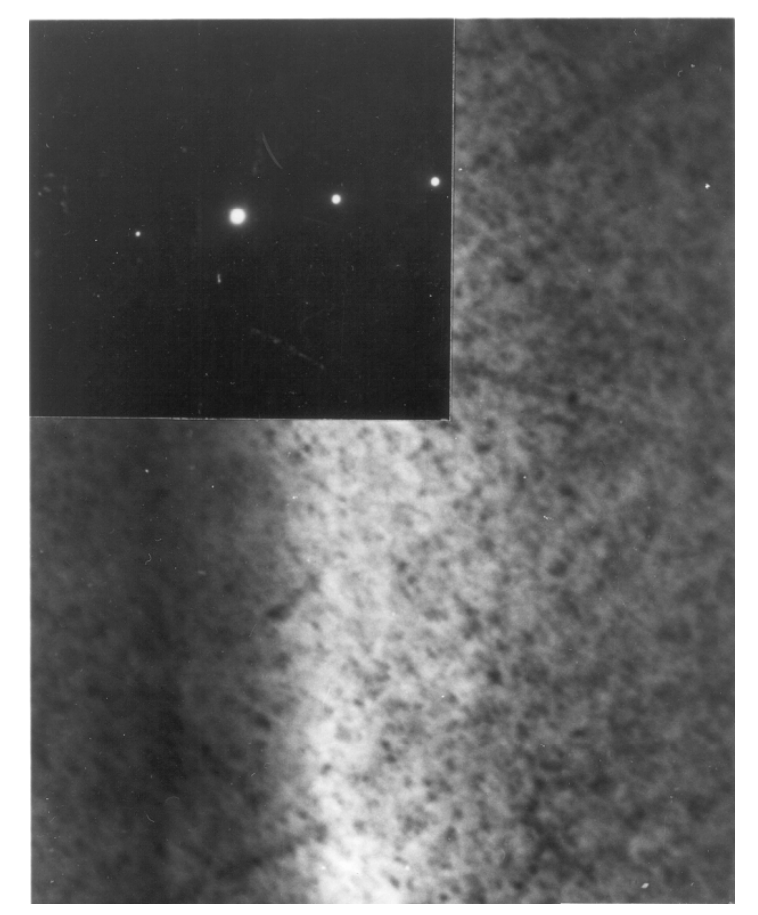

$0.6 \times 10^{18} \alpha$-decays/g

Fission Tracks Alpha-Recoil Tracks

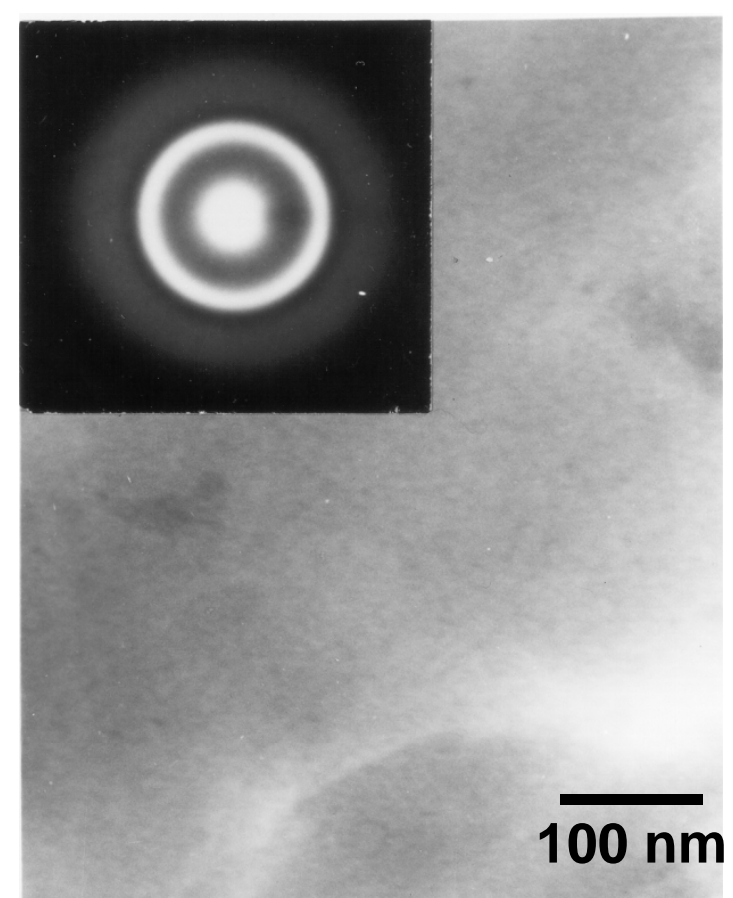

$3.4 \times 10^{18} \alpha$-decays $/ g$

Amorphous

From Weber, Wald \& Matzke, J. Nuclear Materials (1986) 


\section{Dose Dependence: Large Time Scale Range}

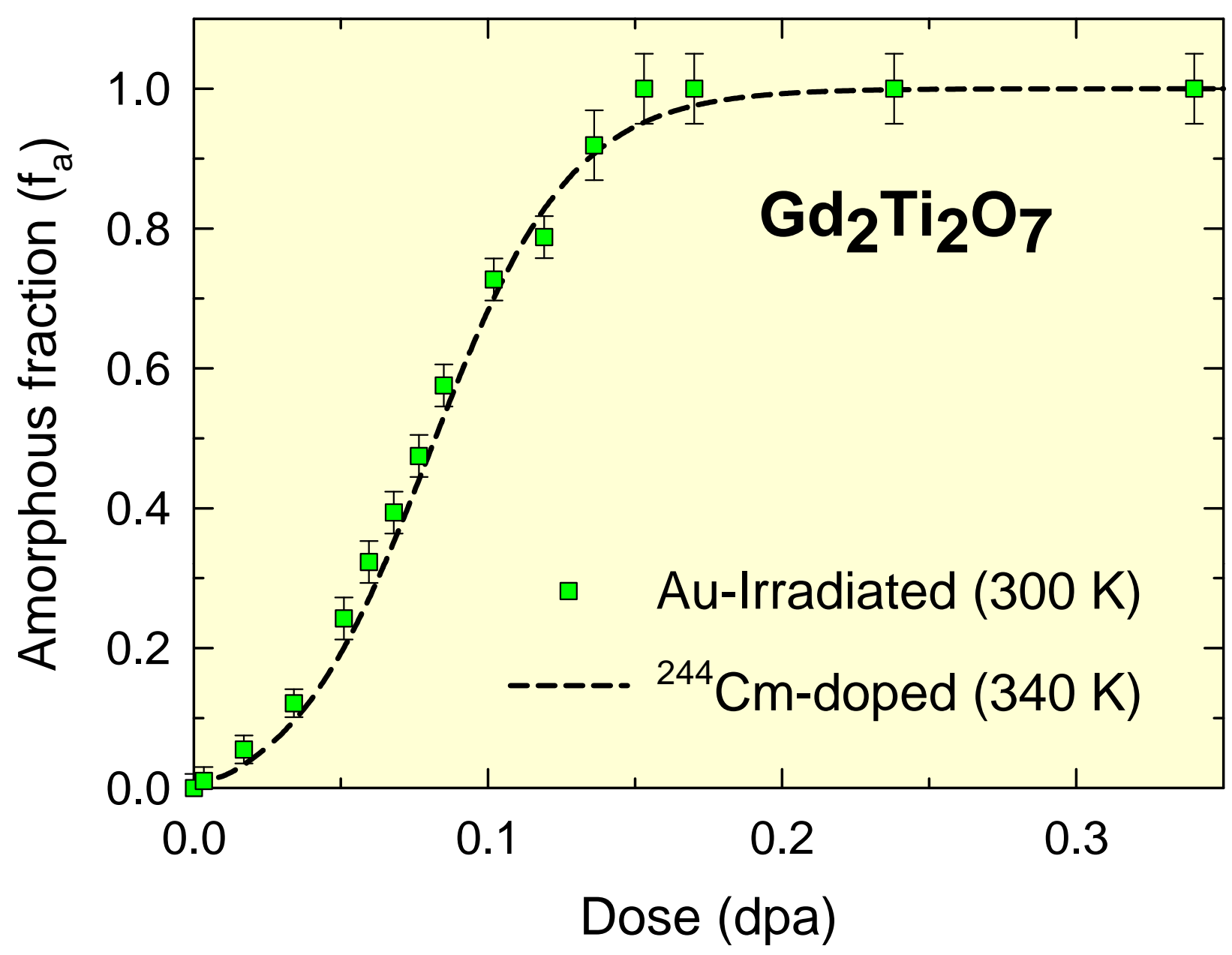

Ion Irradiation (minutes) \& alpha decay (years) results in excellent agreement OAK 


\section{$\mathrm{Gd}_{2} \mathrm{Ti}_{2} \mathrm{O}_{7}:$ Temperature Dependence}

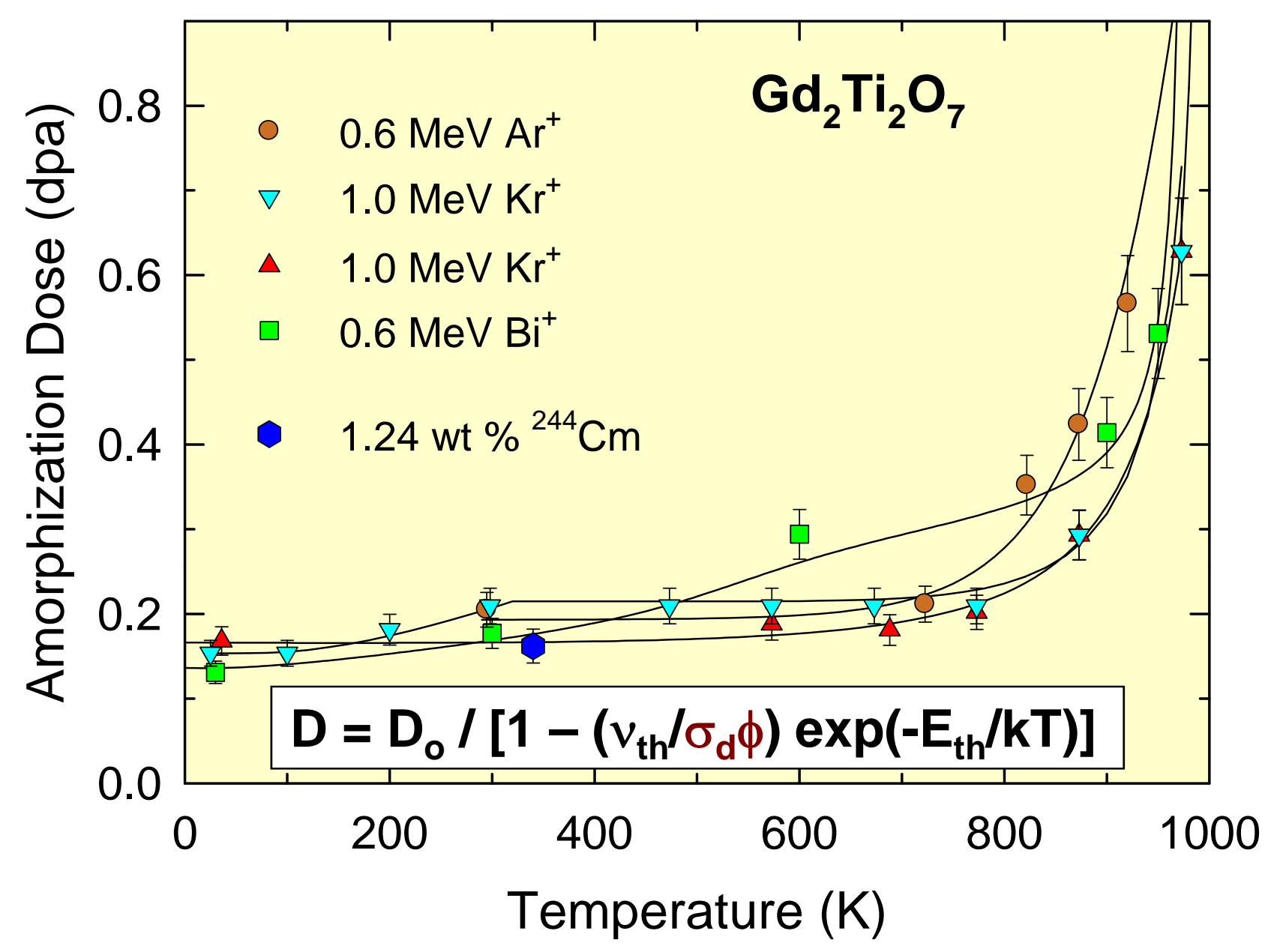

Such data can be used to predict long-term behavior of actinide waste forms 


\section{Model Predictions Based on Experiment Data}

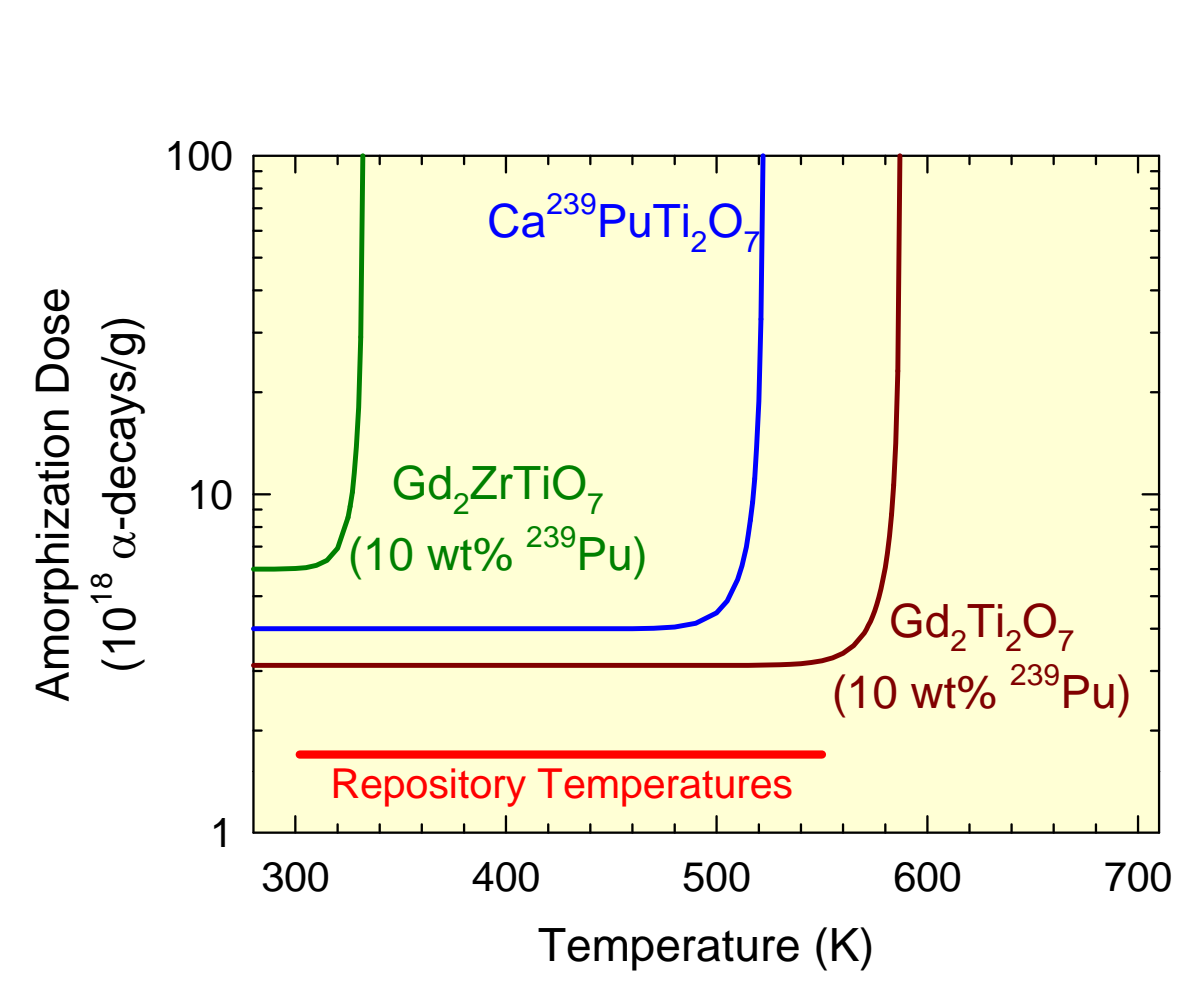

Temperature Dependence

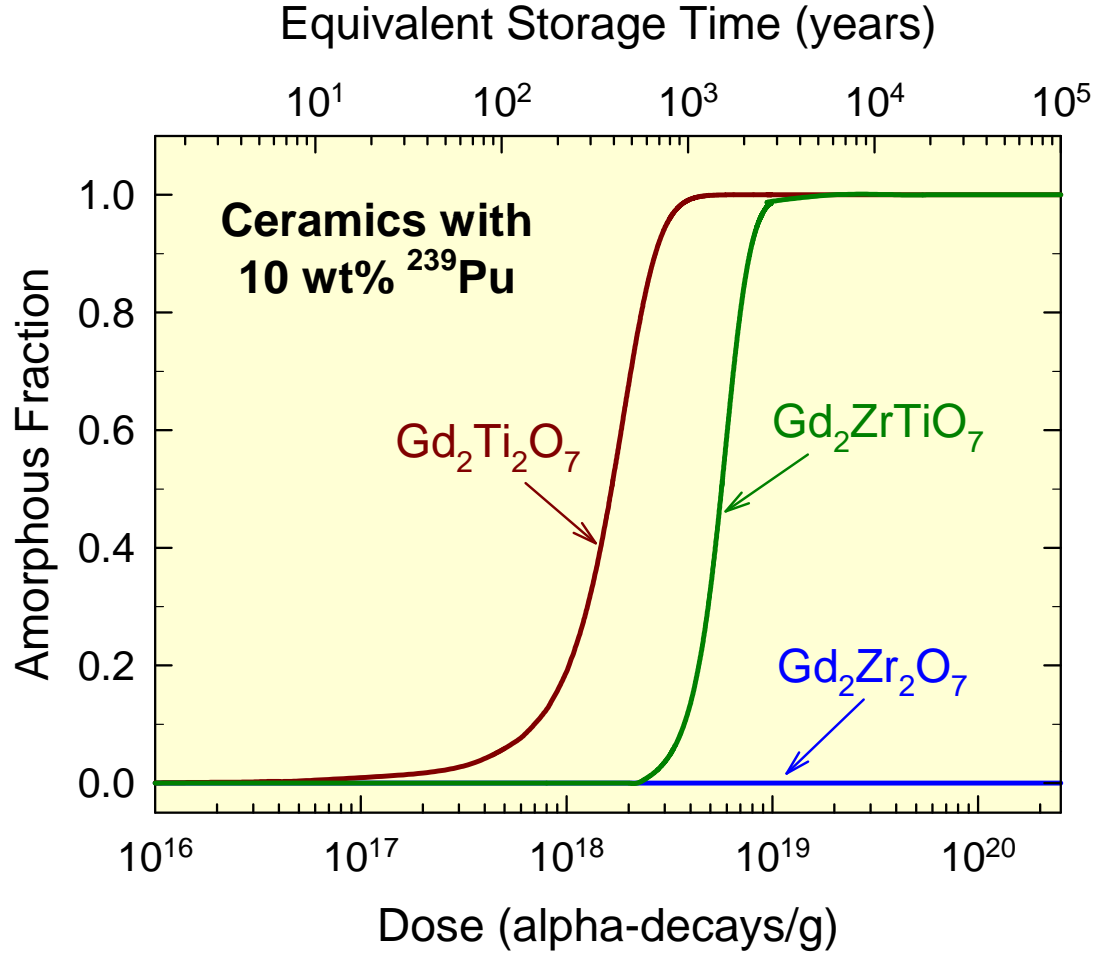

Dose/Time Dependence 


\section{Summary on Use of Ion Beams to Study Radiation Effects in Nuclear Materials}

$>$ Be aware of dose rate effects (temperature shifts)

$>$ Be aware of mass difference effects (recoil spectra)

$>$ Ion irradiations should complement in-reactor testing or other bulk irradiation (short-lived actinides)

$>$ Ion irradiation studies can be used to guide in-reactor or bulk irradiation testing for model validation

$>$ Ion beams can be used to more precisely control irradiation conditions and parameters to study separate effects and develop/validate models

$>$ Ion beams can be used to achieve high doses currently unachievable (structural materials and waste forms) 